\title{
Dissociation Channels of the 1-Buten-2-yl Radical and Its Photolytic Precursor 2-Bromo-1-butene
}

\author{
Johanna L. Miller, Maria J. Krisch, and Laurie J. Butler* \\ The James Franck Institute and The Department of Chemistry, The University of Chicago, \\ Chicago, Illinois 60637
}

\author{
Jinian Shu \\ Chemical Sciences Division, Lawrence Berkeley National Laboratory, Berkeley, California 94720 \\ Received: September 3, 2004; In Final Form: March 7, 2005
}

\begin{abstract}
The work presented here is the first in a series of studies that use a molecular beam scattering technique to investigate the unimolecular reaction dynamics of $\mathrm{C}_{4} \mathrm{H}_{7}$ radical isomers. Photodissociation of the halogenated precursor 2-bromo-1-butene at $193 \mathrm{~nm}$ under collisionless conditions produced 1-buten-2-yl radicals with a range of internal energies spanning the predicted barriers to the unimolecular reaction channels of the radical. Resolving the velocities of the stable $\mathrm{C}_{4} \mathrm{H}_{7}$ radicals, as well as those of the products, allows for the identification of the energetic onset of each dissociation channel. The data show that radicals with at least $30.7 \pm 2 \mathrm{kcal} /$ mol of internal energy underwent $\mathrm{C}-\mathrm{C}$ fission to form allene + methyl, and radicals with at least $36.7 \pm 4$ $\mathrm{kcal} / \mathrm{mol}$ of internal energy underwent $\mathrm{C}-\mathrm{H}$ fission to form $\mathrm{H}+1$-butyne and $\mathrm{H}+1$,2-butadiene; both of these observed barriers agree well with the G3//B3LYP calculations of Miller. HBr elimination from the parent molecule was observed, producing vibrationally excited 1-butyne and 1,2-butadiene. In the subsequent dissociation of these $\mathrm{C}_{4} \mathrm{H}_{6}$ isomers, the major channel was $\mathrm{C}-\mathrm{C}$ fission to form propargyl + methyl, and there is also evidence of at least one of the possible $\mathrm{H}+\mathrm{C}_{4} \mathrm{H}_{5}$ channels. A minor $\mathrm{C}-\mathrm{Br}$ fission channel produces 1-buten-2-yl radicals in an excited electronic state and with low kinetic energy; these radicals exhibit markedly different dissociation dynamics than do the radicals produced in their ground electronic state.
\end{abstract}

\section{Introduction}

Unsaturated hydrocarbon radicals play important roles as intermediates in combustion reactions. Measurements of the competition between the reaction channels available to such radicals provide a benchmark for testing the ability of electronic structure methods and dynamical theories to describe elementary combustion reactions. The experiment described in this paper utilizes a new method introduced by Mueller et al. ${ }^{1}$ for studying the unimolecular reaction dynamics of radicals under collisionless conditions. The radical isomer of interest is created by photolyzing a halogenated precursor in a molecular beam. This photolysis disperses the nascent radicals by the recoil kinetic energy imparted in the carbon-halogen fission, which, due to conservation of energy, is complementary to the internal energy of the radicals. In those radicals that subsequently undergo $\mathrm{C}-\mathrm{H}$ fission, the recoil of the light $\mathrm{H}$ atom imparts negligible additional recoil velocity to the heavier cofragment, which means that the $\mathrm{C}-\mathrm{H}$ fission products are dispersed according to the internal energy of the radicals from which they came. This product velocity determination therefore provides information not only about the energetic onset of each unimolecular dissociation channel of the radical, but also about the change in product branching as a function of the internal energy of the radical.

Mueller et al. ${ }^{1}$ investigated the unimolecular dissociation of the 2-propenyl radical, using 2-chloropropene as a photolytic

* To whom correspondence should be addressed: e-mail L-Butler@ uchicago.edu. precursor. Each of the two dissociation channels available to the 2-propenyl radical involves $\mathrm{C}-\mathrm{H}$ fission (to form $\mathrm{H}+$ allene and $\mathrm{H}+$ propyne), so all of the dissociation products were easily mapped to the internal energies of the 2-propenyl radicals from which they came. This method was later used to study the dissociation of the 1-propenyl radical ${ }^{2,3}$ (via the precursor cis1-bromopropene), which can undergo $\mathrm{C}-\mathrm{C}$ fission to form acetylene + methyl. Because $\mathrm{C}-\mathrm{C}$ fission imparts significant recoil to both of the nascent fragments, the data analysis for this system was more complicated, but the method was ultimately successful. The allyl radical has also been studied using this method, via the precursors allyl chloride ${ }^{4}$ and allyl iodide. $^{5}$

In the studies described above, some of the 2-chloropropene, 1-bromopropene, and allyl chloride molecules underwent HX elimination instead of $\mathrm{C}-\mathrm{X}$ fission. (HI elimination was not observed in the study of allyl iodide.) Because the endothermicity of $\mathrm{HX}$ elimination is less than that of $\mathrm{C}-\mathrm{X}$ fission, some or all of the allene and propyne cofragments to HX elimination were formed with enough energy to undergo secondary dissocation. In each instance, the majority of the $\mathrm{C}_{3} \mathrm{H}_{4}$ cofragments due to $\mathrm{HX}$ elimination underwent $\mathrm{C}-\mathrm{H}$ fission to form $\mathrm{H}+$ propargyl.

With this work, the photodissociation of 2-bromo-1-butene $\left(\mathrm{CH}_{2}=\mathrm{CBrCH}_{2} \mathrm{CH}_{3}\right)$, we begin our experimental investigation of the $\mathrm{C}_{4} \mathrm{H}_{7}$ system, the next smallest system of singly unsaturated hydrocarbon radicals, on which little previous experimental work has been done. Theoretical energies of the stationary points associated with the unimolecular reaction 
channels of the straight-chain $\mathrm{C}_{4} \mathrm{H}_{7}$ radical isomers have been calculated at the G3//B3LYP level by Miller; ${ }^{6}$ the reaction channels available to all $\mathrm{C}_{4} \mathrm{H}_{7}$ isomers have also been briefly considered by Matheu et al. ${ }^{7}$ Available to the 1-buten-2-yl radical $\left(\mathrm{CH}_{2} \dot{\mathrm{C}} \mathrm{CH}_{2} \mathrm{CH}_{3}\right.$, of which 2-bromo-1-butene is the photolytic precursor) are three bond-fission channels and three H-migration channels. In comparison, the 1-propenyl and 2-propenyl radicals each have two available bond fission channels, and the allyl radical has one.

The unimolecular dissociation of 1-buten-2-yl and other $\mathrm{C}_{4} \mathrm{H}_{7}$ radicals is relevant to recent experimental work involving the kinetics of reactions under bulk conditions. ${ }^{8,9}$ Kinetics experiments provide useful data with which to compare predictions of microcanonical rate constants and $a b$ initio barrier heights. However, modeling such experiments requires the use of master equations to describe the adduct formation and complex energy transfer processes also contributing to the bulk measurements. (See, for example, recent work on the propargyl + propargyl system by Klippenstein and Miller. ${ }^{10}$ ) The data presented in this work serve as a more direct test of microcanonical rate constants and theoretical barrier heights.

In addition to the dissociation of the 1-buten-2-yl radical, this experiment allows us to observe the unimolecular dissociation of the 1-butyne $\left(\mathrm{HC} \equiv \mathrm{CCH}_{2} \mathrm{CH}_{3}\right)$ and 1,2-butadiene $\left(\mathrm{H}_{2} \mathrm{C}=\mathrm{C}=\right.$ $\mathrm{CHCH}_{3}$ ) cofragments to $\mathrm{HBr}$ elimination from parent 2-bromo1-butene molecules excited at $193 \mathrm{~nm}$. These $\mathrm{C}_{4} \mathrm{H}_{6}$ molecules have many more reaction channels open to them than did the $\mathrm{C}_{3} \mathrm{H}_{4}$ cofragments to $\mathrm{HX}$ elimination in the $\mathrm{C}_{3} \mathrm{H}_{5} \mathrm{X}$ studies. Some of these channels are detailed in an ab initio study by Lee et al. ${ }^{11}$ Both of these $\mathrm{C}_{4} \mathrm{H}_{6}$ isomers can undergo $\mathrm{C}-\mathrm{C}$ fission to form propargyl + methyl, and each can undergo $\mathrm{C}-\mathrm{H}$ fission in several ways to form a number of different $\mathrm{C}_{4} \mathrm{H}_{5}$ isomers.

\section{Experimental Section}

All data presented here were collected at Endstation 1 of the Chemical Dynamics Beamline (9.0.2) of the Advanced Light Source (ALS) at Lawrence Berkeley National Laboratory. We produced the 1-buten-2-yl radicals by photodissociating 2-bromo1-butene at $193 \mathrm{~nm}$. The experimental method has been described in detail elsewhere, so we provide a summary here. ${ }^{1,5}$ The 2-bromo-1-butene was obtained commercially and used without further purification. The molecular beam of $9 \%$ 2-bromo-1-butene seeded in 900 Torr of helium was expanded through a room-temperature pulsed nozzle with an orifice 1 millimeter in diameter and subsequently skimmed. The measured number-density velocity distribution of the molecular beam peaked at $1.0 \times 10^{5} \mathrm{~cm} / \mathrm{s}$ with a FWHM of $12 \%$.

The 2-bromo-1-butene molecules were photodissociated using the $193 \mathrm{~nm}$ output of a Lambda Physik excimer laser operating at the ArF transition. The laser light was unpolarized in the plane defined by the molecular beam and the detector. The output laser pulse energy was approximately $10 \mathrm{~mJ} /$ pulse throughout the experiment; this pulse energy was chosen based on power-dependence studies of the masses of several fragments of interest, to ensure that the contribution of multiphoton chemistry is negligible. The laser beam was focused to an 8 $\mathrm{mm}^{2}$ spot in the interaction region of the apparatus. The pulsed nozzle frequency was kept constant at $100 \mathrm{~Hz}$. The laser was operated at $100 \mathrm{~Hz}$ when shot-to-shot background subraction was not used, and at $50 \mathrm{~Hz}$ when it was used.

Photofragments reaching the detector were ionized by the tunable vacuum ultraviolet radiation of the ALS. Throughout the experiment, the dimensions of the beam-defining aperture were set to $10 \mathrm{~mm} \times 10 \mathrm{~mm}$, resulting in a distribution of

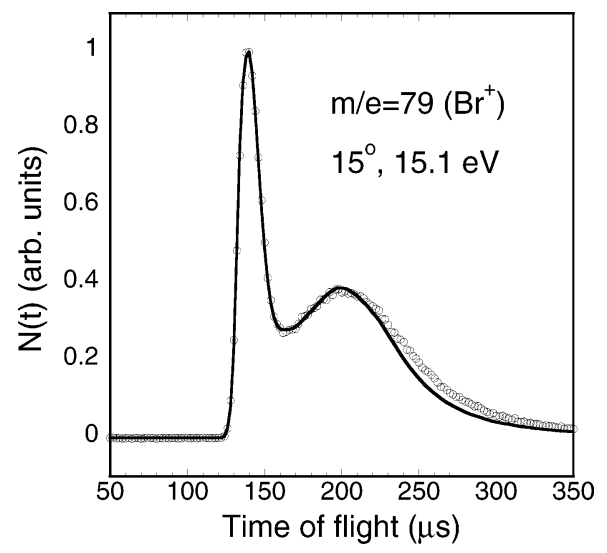

Figure 1. Time-of-flight spectrum of $m / e=79\left(\mathrm{Br}^{+}\right)$, with a source angle of $15^{\circ}$ and a photoionization energy of $15.1 \mathrm{eV}$. Data are shown in open circles, and the solid line is the forward convolution fit from the energy distribution shown in Figure 2. The slightly underfit signal at arrival times greater than $200 \mu \mathrm{s}$ is too slow to be due to photodissociation of 2-bromo-1-butene or its dimer, and may be the result of beam scatter.

photon energies with a FWHM of about $5.5 \%$, which is not symmetric about the mean but is shaded to the red. ${ }^{12}$ The ionized fragments were filtered by mass-to-charge ratio with a quadrupole. The time-of-flight (TOF) spectra of the mass-selected photofragments include not only the flight time of the neutral species through the $15.2 \mathrm{~cm}$ flight path from the interaction region to the detector, but also the ion flight time through the mass spectrometer. The ion fight time constants were $5.75 \mu \mathrm{s} /$ $\mathrm{amu}^{1 / 2}$ for $m / e \leq 40$, and $7.14 \mu \mathrm{s} / \mathrm{amu}^{1 / 2}$ for higher masses (different quadrupoles were used for fragments with $m / e \leq 40$ and fragments with higher masses). Where indicated, a $\mathrm{MgF}_{2}$ window was used to filter the blue tail of the ionizing radiation.

\section{Results and Analysis}

3.1. Primary Photodissociation Channels of 2-Bromo-1butene. We observed two significant primary dissociation channels of 2-bromo-1-butene. The major channel, $\mathrm{C}-\mathrm{Br}$ fission to form $\mathrm{Br}$ plus the 1-buten-2-yl radical, is characterized by the TOF spectrum at $m / e=79\left(\mathrm{Br}^{+}\right)$, shown in Figure 1. The translational energy distribution $\left(\mathrm{P}\left(\mathrm{E}_{\mathrm{T}}\right)\right)$ for $\mathrm{C}-\mathrm{Br}$ fission was derived from the forward convolution fitting of this spectrum, and is shown as the dotted line in Figure 2. This distribution is bimodal, and our observations regarding the subsequent dissociation of the momentum-matched $\mathrm{C}_{4} \mathrm{H}_{7}$ radicals suggest that the low-kinetic-energy $\mathrm{C}-\mathrm{Br}$ fission channel produces 1-buten2 -yl radicals in an excited electronic state. Recent calculations by Levchenko and Krylov confirm the existence of such a lowlying excited state; ${ }^{13}$ this point is addressed more thoroughly in the Discussion. The minor primary channel, $\mathrm{HBr}$ elimination, is characterized by the TOF spectrum at $m / e=80\left(\mathrm{H}^{79} \mathrm{Br}^{+}\right)$, shown in Figure 3. The corresponding $\mathrm{P}\left(\mathrm{E}_{\mathrm{T}}\right)$ derived from fitting the $\mathrm{HBr}^{+}$data is shown in Figure 4 .

Due to time constraints at the synchrotron, we did not investigate the anisotropy of these primary processes. If the lowkinetic-energy and high-kinetic-energy $\mathrm{C}-\mathrm{Br}$ fission processes contributing to the $m / e=79$ spectrum have differing anisotropies, it would be necessary to correct each of their relative contributions to the $\mathrm{P}\left(\mathrm{E}_{\mathrm{T}}\right)$ by a factor of $(1+\beta / 4)^{-1}$. In studies of the photodissociation of analogous halogenated unsaturated hydrocarbons resulting from excitation in the $\pi \pi^{*}$ absorption band, the anisotropy of the carbon-halogen fission has typically been found to be small, ${ }^{14}$ due in part to the existence of multiple 


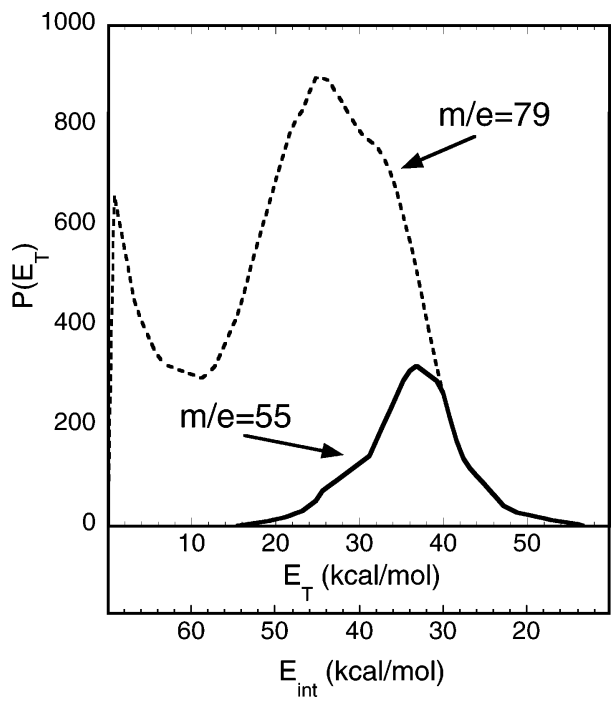

Figure 2. The dotted line is the translational energy distribution, $P\left(\mathrm{E}_{\mathrm{T}}\right)$, derived from the forward convolution fit to the $\mathrm{Br}^{+}$spectrum shown in Figure 1. The upper axis, $E_{\mathrm{T}}$, is the total kinetic energy of the momentum-matched fragments, $\mathrm{Br}$ and 1-buten-2-yl. The lower axis, $E_{\text {int }}$, is the corresponding internal energy of the 1-buten-2-yl radical derived from equation 2 . The solid line is the $P\left(\mathrm{E}_{\mathrm{T}}\right)$ derived from the forward convolution fit to the $m / e=55$ spectrum shown in Figure 6, and corresponds to stable 1-buten-2-yl radicals.

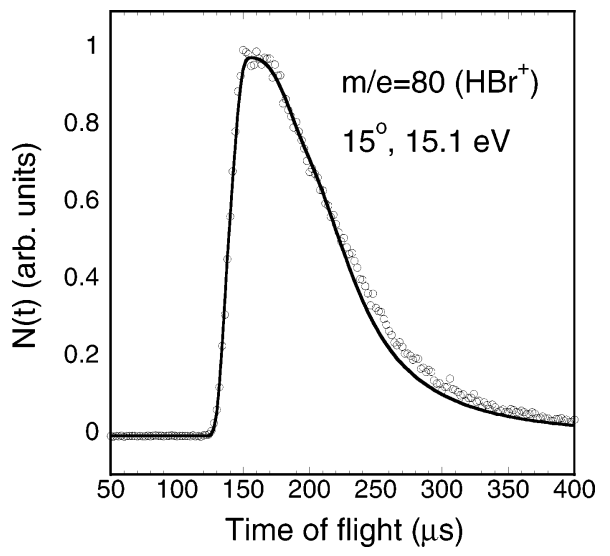

Figure 3. Time-of-flight spectrum of $m / e=80\left(\mathrm{HBr}^{+}\right)$, with a source angle of $15^{\circ}$ and a photoionization energy of $15.1 \mathrm{eV}$. Data are shown in open circles, and the solid line is the forward convolution fit from the energy distribution shown in Figure 4. The slightly underfit signal at arrival times greater than $200 \mu \mathrm{s}$ is too slow to be due to photodissociation of 2-bromo-1-butene or its dimer, and may be the result of beam scatter.

ground-state conformers. The necessary correction factor is therefore expected to be quite small.

We searched for the following primary dissociation channels by collecting TOF spectra at the parent ion masses of the bromine-containing fragments: $\mathrm{CH}_{2} \mathrm{CBr}+\mathrm{CH}_{2} \mathrm{CH}_{3} ; \mathrm{CH}_{2} \mathrm{CHBr}$ $+\mathrm{C}_{2} \mathrm{H}_{4} ; \mathrm{CH}_{2} \mathrm{CBrCH}_{2}+\mathrm{CH}_{3}$; and $\mathrm{C}_{3} \mathrm{H}_{3} \mathrm{Br}+\mathrm{CH}_{4}$. No signal was observed at $m / e=106\left(\mathrm{CH}_{2} \mathrm{CHBr}^{+}\right), m / e=118\left(\mathrm{C}_{3} \mathrm{H}_{3}-\right.$ $\left.\mathrm{Br}^{+}\right)$, or $m / e=119\left(\mathrm{CH}_{2} \mathrm{CBrCH}_{2}{ }^{+}\right)$. Signal of a small magnitude was observed at $m / e=105\left(\mathrm{CH}_{2} \mathrm{CBr}^{+}\right)$, but we were unable to determine whether this was due to photodissociation of 2-bromo1-butene or of its dimer. We did not check directly for $\mathrm{C}-\mathrm{H}$ fission or $\mathrm{H}_{2}$ elimination from the parent 2-bromo-1-butene molecules, so we cannot rule out the possibility of these channels, but most of the spectra are adequately fit without these channels.

3.1.1. C-Br Fission to Form Br+1-Buten-2-yl. The internal energy, $E_{\text {int }}(1-$ buten-2-yl), of the nascent 1-buten-2-yl radicals

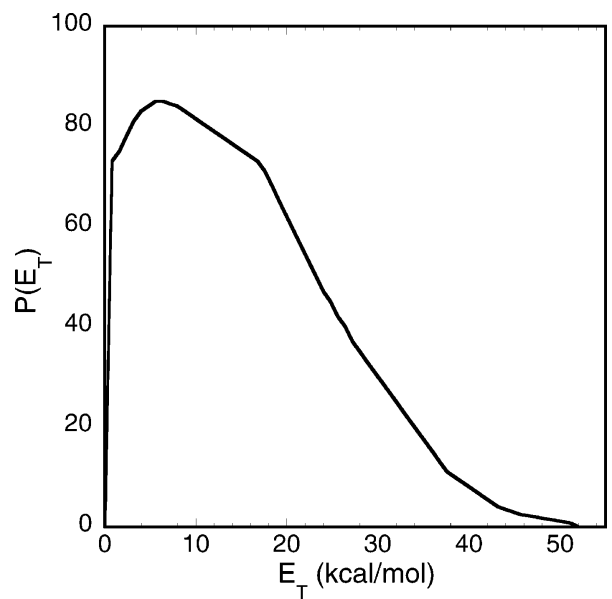

Figure 4. Translational energy distribution, $P\left(\mathrm{E}_{\mathrm{T}}\right)$, derived from the forward convolution fit to the $\mathrm{HBr}^{+}$spectrum shown in Figure 3 .

may be found using the law of conservation of energy:

$$
\begin{aligned}
h v+E_{\text {int }}(\text { precursor })= & D_{\mathrm{o}}(C-B r)+E_{\mathrm{T}}+ \\
& E_{\text {int }}(1-\text { buten-2-yl })+E_{\text {int }}(\mathrm{Br})
\end{aligned}
$$

Here, $h v=148.0 \mathrm{kcal} / \mathrm{mol}$, the energy of a $193.3 \mathrm{~nm}$ photon. $E_{\text {int }}$ (precursor) is the total internal energy of the parent 2-bromo1-butene molecules. Because of the cooling of the molecular rotations in the supersonic expansion, we may use the vibrational energy of the parent molecules as an approximation to $E_{\text {int }}{ }^{-}$ (precursor). Assuming that the vibrational temperature of the beam is closely approximated by the temperature of the nozzle $\left(25^{\circ} \mathrm{C}\right)$, and using unscaled vibrational frequencies calculated at the B3LYP/6-311G(d,p) level, with an effective core potential for the bromine atom, ${ }^{15}$ we find the mean value of $E_{\text {int }}$ (precursor) to be $2.3 \mathrm{kcal} / \mathrm{mol}$. From calculations using the $\mathrm{G} 2 \mathrm{M}(\mathrm{CC}, \mathrm{MP} 2)$ method $^{16}$ (again, using an effective core potential for the bromine atom), we find $D_{0}(\mathrm{C}-\mathrm{Br})$, the carbon-bromine bond dissociation energy, to be $80.4 \mathrm{kcal} / \mathrm{mol}$. (For these and all the other electronic structure calculations we performed, we used the Gaussian 98 program, revision A.11.3. ${ }^{17}$ )

$E_{\text {int }}(\mathrm{Br})$, the internal energy of the bromine atom, is either 0 $\mathrm{kcal} / \mathrm{mol}$ (for bromine atoms in the ${ }^{2} \mathrm{P}_{3 / 2}$ spin-orbit state) or $10.5 \mathrm{kcal} / \mathrm{mol}$ (for bromine atoms in the ${ }^{2} \mathrm{P}_{1 / 2}$ spin-orbit state). By considering the dependence of $m / e=79$ signal on photoionization energy, it is evident that bromine atoms are formed predominantly in the ${ }^{2} \mathrm{P}_{3 / 2}$ spin-orbit state. Integrated $m / e=$ 79 signal at $11.5 \mathrm{eV}$ was 16567 counts in 60000 laser shots. Integrated signal at $12.5 \mathrm{eV}$ was 140656 counts in 30000 laser shots. This results in a 12.5:11.5 eV ratio of 16.9 , in good agreement with the ratio of $16.10 \pm 1.37$ for the $\operatorname{Br}\left({ }^{2} \mathrm{P}_{3 / 2}\right)$ atoms produced in the photodissociation of methyl bromide. ${ }^{3}$ Therefore:

$$
E_{\text {int }}(1 \text {-buten-2-yl })=69.9 \mathrm{kcal} / \mathrm{mol}-E_{\mathrm{T}}
$$

The distribution of translational energies imparted in $\mathrm{C}-\mathrm{Br}$ bond fission ranges from 0 to $56.0 \mathrm{kcal} / \mathrm{mol}$, as shown in the dotted-line $P\left(\mathrm{E}_{\mathrm{T}}\right)$ in Figure 2, so $E_{\mathrm{int}}(1$-buten-2-yl) (henceforth, simply $E_{\text {int }}$ ) ranges from 13.9 to $69.9 \mathrm{kcal} / \mathrm{mol}$. This range spans the calculated barriers to the dissociation channels of the nascent 1-buten-2-yl radicals, shown in Figure 5.

3.1.2. $\mathrm{HBr}$ Elimination to Form $\mathrm{HBr}+1$-Butyne or $\mathrm{HBr}+$ 1,2-Butadiene. There exist two four-center $\mathrm{HBr}$ elimination channels available to the 2-bromo-1-butene molecule: one resulting in $\mathrm{HBr}+1$-butyne, and one resulting in $\mathrm{HBr}+1,2-$ 


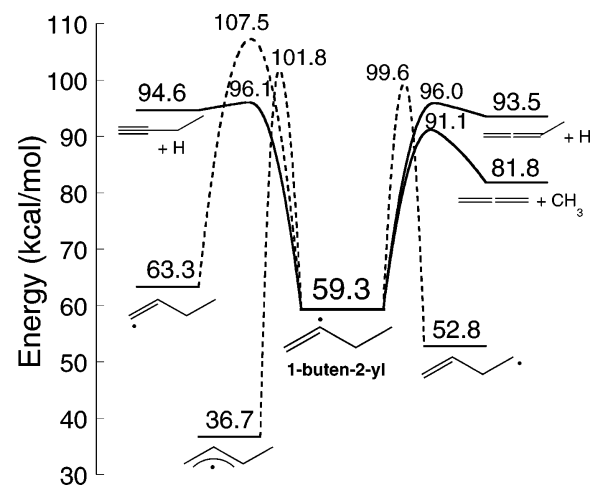

Figure 5. G3//B3LYP calculated energies (from Miller ${ }^{6}$ ) of the species involved in the unimolecular reaction channels of the 1-buten-2-yl radical. Dotted lines represent isomerization channels, and solid lines represent dissociation channels. Some of these channels proceed through two distinct transition states, with different values of the CCCC dihedral angle; in these instances we give the energy of the lower-energy transition state.

butadiene. These are similar to the $\mathrm{HCl}$ elimination channels of 2-chloropropene, leading to $\mathrm{HCl}+$ propyne and $\mathrm{HCl}+$ allene, studied theoretically by Parsons et al. ${ }^{18}$ Even though those authors found that the freezing of the methyl rotor substantially reduced the RRKM-predicted branching to the allene channel, they still found that the predicted branching to both channels was significant.

Using the G2M(CC,MP2) method, with an effective core potential on the bromine atom, we found that there are two transition states leading to $\mathrm{HBr}+1$-butyne, with $\mathrm{BrC}_{2} \mathrm{C}_{3} \mathrm{C}_{4}$ dihedral angles of $180^{\circ}$ and $59.9^{\circ}$. The zero-point-corrected energies of these transition states, relative to 2-bromo-1-butene, are respectively 65.8 and $63.9 \mathrm{kcal} / \mathrm{mol}$. There is only one transition state leading to $\mathrm{HBr}+1,2$-butadiene, with an energy of $64.8 \mathrm{kcal} / \mathrm{mol}$. At an excitation energy of $150.0 \mathrm{kcal} / \mathrm{mol}$, the sums of states (appearing in the numerator of the RRKM rate constant ${ }^{19}$ ) at all three transition states are roughly equal, so the $\mathrm{C}_{4} \mathrm{H}_{6}$ cofragments to $\mathrm{HBr}$ elimination are expected to comprise a mixture of 1-butyne and 1,2-butadiene.

From our G2M(CC,MP2) calculations, the endothermicity at $0 \mathrm{~K}$ of the 1-butyne channel is $28.3 \mathrm{kcal} / \mathrm{mol}$, and the endothermicity at $0 \mathrm{~K}$ of the 1,2-butadiene channel is $26.9 \mathrm{kcal} /$ mol. Lin et al. ${ }^{20}$ found that four-center $\mathrm{HBr}$ elimination from vinyl bromide produces $\mathrm{HBr}$ molecules with an average of 17.0 $\mathrm{kcal} / \mathrm{mol}$ of vibrational plus rotational energy. Using this value as an estimate of the average internal energy of the $\mathrm{HBr}$ molecules produced from 2-bromo-1-butene, we obtain the very rough estimate that approximately $105 \mathrm{kcal} / \mathrm{mol}$ is available for recoil kinetic energy plus internal energy of the cofragment.

3.2. Unimolecular Dissociation Channels of the 1-Buten2-yl Radical. Figure 5 shows the unimolecular reaction channels available to the 1-buten-2-yl radical. Energies, structures, and vibrational frequencies of the relevant stationary points on the potential energy surface were calculated by Miller ${ }^{6}$ using the G3//B3LYP method. ${ }^{21}$ At an internal energy of $70 \mathrm{kcal} / \mathrm{mol}$, the RRKM-predicted branching ${ }^{19}$ to all of the isomerization channels combined is less than $1 \%$. At lower internal energies, the branching to isomerization is lower still. We conclude that we may safely focus our attention on the three dissociation channels: $\mathrm{C}-\mathrm{C}$ fission to form allene $\left(\mathrm{H}_{2} \mathrm{C}=\mathrm{C}=\mathrm{CH}_{2}\right)+$ methyl; $\mathrm{C}-\mathrm{H}$ fission to form $\mathrm{H}+1$-butyne $\left(\mathrm{HC} \equiv \mathrm{CCH}_{2} \mathrm{CH}_{3}\right)$; and $\mathrm{C}-\mathrm{H}$ fission to form $\mathrm{H}+$ 1,2-butadiene $\left(\mathrm{H}_{2} \mathrm{C}=\mathrm{C}=\mathrm{CHCH}_{3}\right)$.

3.2.1. Stable 1-Buten-2-yl Radicals. The higher-velocity nascent 1-buten-2-yl radicals, momentum-matched to the highervelocity $\mathrm{Br}$ atoms in Figure 1, have correspondingly low internal

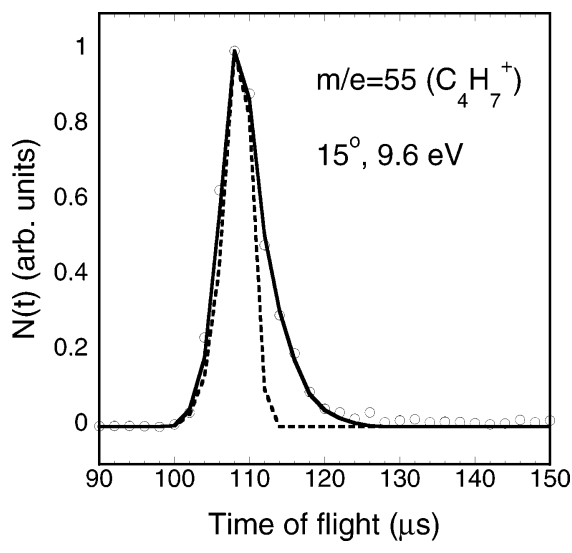

Figure 6. Time-of-flight spectrum of $m / e=55\left(\mathrm{C}_{4} \mathrm{H}_{7}{ }^{+}\right)$, with a source angle of $15^{\circ}$ and a photoionization energy of $9.6 \mathrm{eV}$, with the $\mathrm{MgF}_{2}$ window in place. The solid line is the forward convolution fit calculated from the $P\left(\mathrm{E}_{\mathrm{T}}\right)$ in Figure 7 . The dotted line is an unsatisfactory fit calculated from the $P\left(\mathrm{E}_{\mathrm{T}}\right)$ obtained by truncating the $P\left(\mathrm{E}_{\mathrm{T}}\right)$ in Figure 2 at an $E_{\mathrm{T}}$ of $34.4 \mathrm{kcal} / \mathrm{mol}$. It follows that there is a range of translational energies over which some of the 1-buten-2-yl radicals are stable and some are not.

energies, so they are expected to be stable to secondary dissociation. The TOF spectrum at $m / e=55\left(\mathrm{C}_{4} \mathrm{H}_{7}{ }^{+}\right)$, shown in Figure 6, is momentum-matched to the fastest portion of the $\mathrm{C}-\mathrm{Br}$ fission $P\left(\mathrm{E}_{\mathrm{T}}\right)$, the solid-line $P\left(\mathrm{E}_{\mathrm{T}}\right)$ in Figure 2. Also shown in Figure 6, for comparison, is an unsatisfactory fit obtained by truncating the $\mathrm{C}-\mathrm{Br}$ fission $P\left(\mathrm{E}_{\mathrm{T}}\right)$ at an $E_{\mathrm{T}}$ of $34.4 \mathrm{kcal} /$ mol. Because this fit is much narrower than the observed spectrum, it follows that there is a range of translational energies, from $16.0 \mathrm{kcal} / \mathrm{mol}$ to $39.2 \mathrm{kcal} / \mathrm{mol}$, over which some of the nascent 1-buten-2-yl radicals are stable and some are not. (Cf. Mueller et al. ${ }^{1}$, who were able to obtain a good fit to their spectrum of stable 2-propenyl radicals by sharply truncating their $\mathrm{C}-\mathrm{Cl}$ fission $P\left(\mathrm{E}_{\mathrm{T}}\right)$.) Our experimental determination of the lowest energy barrier to dissociation of the 1-buten-2-yl radical is equal to the smallest value of $E_{\text {int }}$ at which 1-buten-2-yl radicals dissociate, i.e. $69.9-39.2=30.7 \mathrm{kcal} / \mathrm{mol}$. This is in good agreement with the calculated barrier to $\mathrm{C}-\mathrm{C}$ fission of $31.8 \pm 2 \mathrm{kcal} / \mathrm{mol}$, as can be derived from Figure 5 .

The range of translational energies over which some of the radicals are stable is due to a combination of three factors: the production of a small fraction of bromine atoms in the spinorbit excited state; the width of the distribution of vibrational energies in the parent 2-bromo-1-butene molecule; and the width of the distribution of rotational energies imparted to the 1-buten2 -yl radical by the initial $\mathrm{C}-\mathrm{Br}$ fission event. The bromineatom spin-orbit splitting is $10.5 \mathrm{kcal} / \mathrm{mol}$. The average vibrational energy of the parent 2-bromo-1-butene molecules at the nozzle temperature is $2.3 \mathrm{kcal} / \mathrm{mol}$. Using a simple model in which the $\mathrm{C}-\mathrm{Br}$ fission imparts an impulse along the line of the dissociating $\mathrm{C}-\mathrm{Br}$ bond, we find that, for translational energy of $30 \mathrm{kcal} / \mathrm{mol}$, the expected rotational energy imparted to the nascent 1-buten-2-yl radical is $1.6 \mathrm{kcal} / \mathrm{mol}$ when the CCCC backbone has cis geometry, and $4.0 \mathrm{kcal} / \mathrm{mol}$ when the backbone has trans geometry. These three factors together account for a range of roughly $20 \mathrm{kcal} / \mathrm{mol}$ over which the 1-buten-2-yl radicals are partially stable; the stable 1-buten-2yl radicals with $E_{\mathrm{T}}$ near $16 \mathrm{kcal} / \mathrm{mol}$ probably result from parent 2-bromo-1-butene molecules that have little initial internal energy, and that undergo $\mathrm{C}-\mathrm{Br}$ fissions that produce the bromine atom in the ${ }^{2} \mathrm{P}_{1 / 2}$ state and impart greater than average rotational energy to the 1-buten-2-yl radical.

3.2.2. $C-H$ Fission to Form $H+1$-Butyne and $H+1,2-$ Butadiene. Two $\mathrm{C}-\mathrm{H}$ fission channels are available to the 


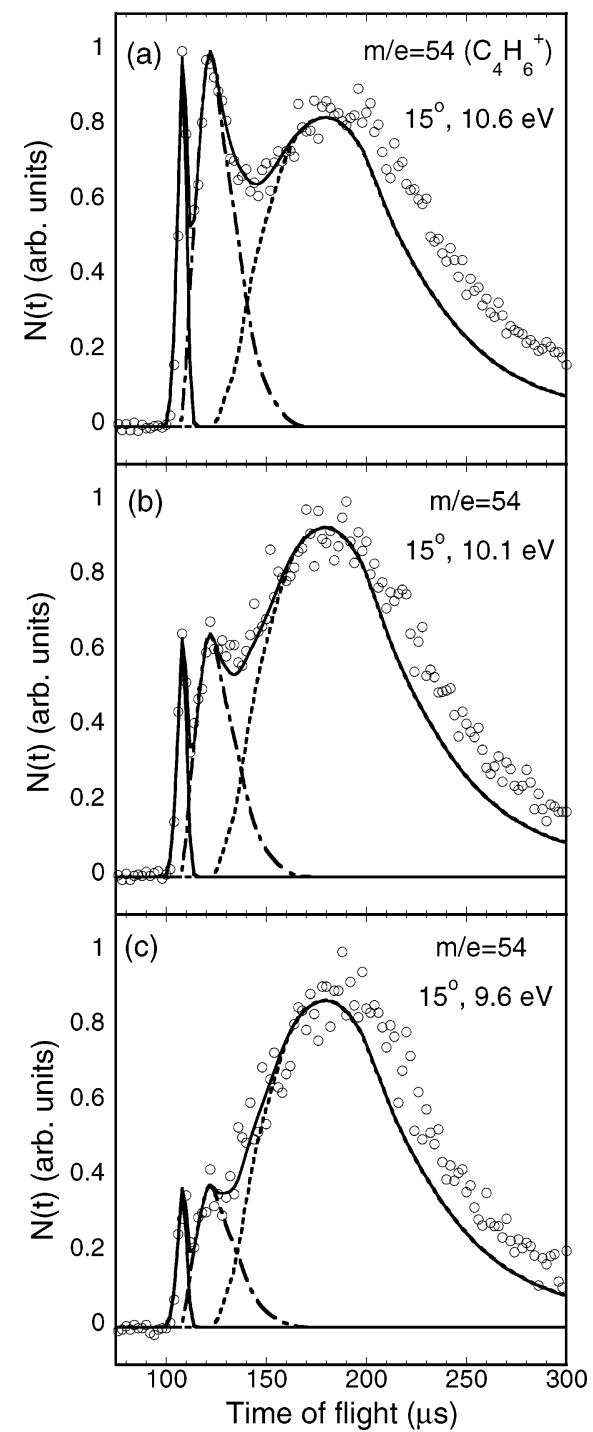

Figure 7. Time-of-flight spectra of $m / e=54\left(\mathrm{C}_{4} \mathrm{H}_{6}{ }^{+}\right)$, with a source angle of $15^{\circ}$ and photoionization energies of $10.6 \mathrm{eV}$ (a), $10.1 \mathrm{eV}(\mathrm{b})$, and $9.6 \mathrm{eV}$ (c). The $\mathrm{MgF}_{2}$ filter was in place for all three of these spectra. The solid-line peak is fit by the fastest portion of the $\mathrm{HBr}$ elimination $P\left(\mathrm{E}_{\mathrm{T}}\right)$ in Figure 4, corresponding to $\mathrm{C}_{4} \mathrm{H}_{6}$ cofragments of $\mathrm{HBr}$ elimination that are stable to secondary dissociation, but this peak may contain a contribution from dissociative ionization of stable 1-buten-2-yl radicals as well. The dotted-dashed and dotted lines are calculated from the dotted-dashed and dotted $\mathrm{P}\left(\mathrm{E}_{\mathrm{T}}\right) \mathrm{s}$ shown in Figure 8 , and correspond to $\mathrm{C}_{4} \mathrm{H}_{6}$ products of $\mathrm{C}-\mathrm{H}$ fission of vibrationally excited 1-buten-2-yl radicals. The underfit signal at arrival times greater than $200 \mu$ s is too slow to be due to photodissociation of 2-bromo-1butene or of its dimer and may be the result of beam scatter.

1-buten-2-yl radical: loss of an $\mathrm{H}$ atom from the 1-carbon to form $\mathrm{H}+1$-butyne, and loss of an $\mathrm{H}$ atom from the 3-carbon to form $\mathrm{H}+1$,2-butadiene. Because the ionization potentials of the two possible $\mathrm{C}_{4} \mathrm{H}_{6}$ products differ substantially $(10.2 \mathrm{eV}$ for 1-butyne, and $9.3 \mathrm{eV}$ for 1,2-butadiene), we used the tunability of the ALS photoionization source to attempt to distinguish between the two isomers. TOF spectra at $m / e=54$ $\left(\mathrm{C}_{4} \mathrm{H}_{6}{ }^{+}\right)$using three different photoionization energies are shown in Figure 7. All three spectra are clearly trimodal, with the relative magnitudes of the peaks changing as a function of internal energy.

The fastest peak, fit with the solid line, is too fast to be the result of $\mathrm{C}-\mathrm{H}$ fission of 1-buten-2-yl radicals. We were able to achieve a satisfactory fit to this peak by using the same $P\left(\mathrm{E}_{\mathrm{T}}\right)$ as was used to fit the $m / e=55$ spectrum, i.e. by assuming that

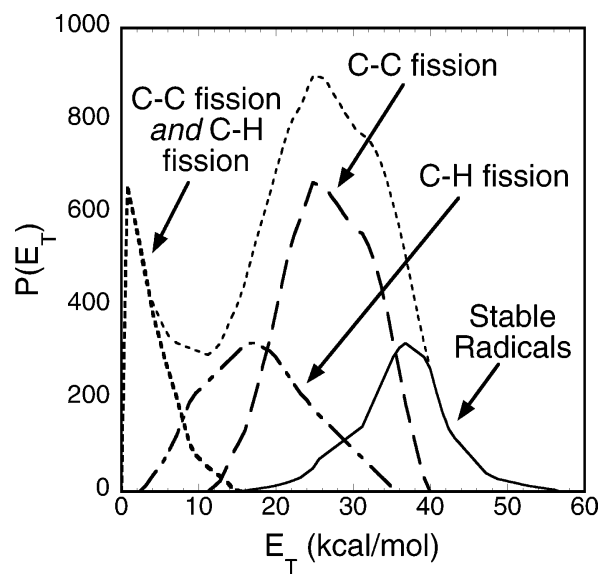

Figure 8. The dotted-dashed line, derived from the forward convolution fit to the middle peak of the spectra in Figure 7 , is the energy distribution of near-threshold 1-buten-2-yl radicals that undergo $\mathrm{C}-\mathrm{H}$ fission. The thick dotted line is derived from the fit to the slowest peak of the spectra in Figure 7; this $P\left(\mathrm{E}_{\mathrm{T}}\right)$ is also used to fit the slow peak of the $m / e=40$ spectrum, which means that some of these radicals undergo $\mathrm{C}-\mathrm{C}$ fission, and some undergo $\mathrm{C}-\mathrm{H}$ fission. The thin solid line is the $P\left(\mathrm{E}_{\mathrm{T}}\right)$ of the stable 1-buten-2-yl radicals, also shown in Figure 2. The dashed line is what remains when these three $P\left(\mathrm{E}_{\mathrm{T}}\right) \mathrm{s}$ are subtracted from the $\mathrm{C}-\mathrm{Br}$ fission $P\left(\mathrm{E}_{\mathrm{T}}\right)$ (the thin dotted line); this distribution provides a good fit to the fast peak of the $m / e=40$ spectrum in Figure 9.

this peak is due to the dissociative ionization of stable 1-buten2 -yl radicals. This peak is also well fit by the fastest portion of the $\mathrm{HBr}$ elimination $P\left(\mathrm{E}_{\mathrm{T}}\right)$, corresponding to $\mathrm{C}_{4} \mathrm{H}_{6}$ products of $\mathrm{HBr}$ elimination that do not have enough energy to undergo subsequent dissociation; this is the fit depicted by the solid line in Figure 7. We are unable to resolve the relative contributions of $\mathrm{HBr}$ elimination cofragments and dissociative ionization of stable 1-buten-2-yl radicals because both give a good fit to the data.

The middle peak (fit by the dashed-dotted line) and the slowest peak (fit by the dotted line) are the result of $\mathrm{C}-\mathrm{H}$ fission of 1-buten-2-yl radicals. The $P\left(\mathrm{E}_{\mathrm{T}}\right) \mathrm{s}$ from which these fits were derived are depicted as the dashed-dotted and dotted lines in Figure 8. Because of the overlap between the fastest and middle peaks, the onset of $\mathrm{C}-\mathrm{H}$ fission is difficult to determine. In the fits shown here, the largest value of $E_{\mathrm{T}}$ for which $\mathrm{C}-\mathrm{H}$ fission is observed is $35.2 \mathrm{kcal} / \mathrm{mol}$, corresponding to an $E_{\text {int }}$ of 34.7 $\mathrm{kcal} / \mathrm{mol}$. We were able to obtain equally good fits to these spectra assuming that $\mathrm{C}-\mathrm{H}$ fission occurs for $E_{\mathrm{T}} \leq 31.2 \mathrm{kcal} /$ mol, corresponding to an $E_{\text {int }}$ of $38.7 \mathrm{kcal} / \mathrm{mol}$. Both of these values are in satisfactory agreement with the calculated barrier height of $36.7 \pm 2 \mathrm{kcal} / \mathrm{mol}$.

The relative magnitudes of the middle and slowest peaks change dramatically as a function of ionization energy. This is not consistent with both peaks resulting from $\mathrm{C}-\mathrm{H}$ fission of 1-buten-2-yl radicals on the ground-state potential energy surface, because the calculated barriers to forming 1-butyne (IE $=10.18 \mathrm{eV})$ and 1,2-butadiene (IE $=9.0$ or $9.3 \mathrm{eV})$ are nearly identical, ${ }^{6}$ so the branching to these two products is not expected to change much as a function of internal energy. There is a strong possibility that the slowest peak results from $\mathrm{C}-\mathrm{H}$ fission of 1-buten-2-yl radicals produced in an excited electronic state. While theoretical understanding of the excited-state dissociation dynamics has not yet been achieved, our results suggest that $\mathrm{C}-\mathrm{H}$ fission from the excited state is significantly more likely to produce $\mathrm{H}+1$,2-butadiene than is $\mathrm{C}-\mathrm{H}$ fission from the ground state. This point is addressed further in the Discussion. 


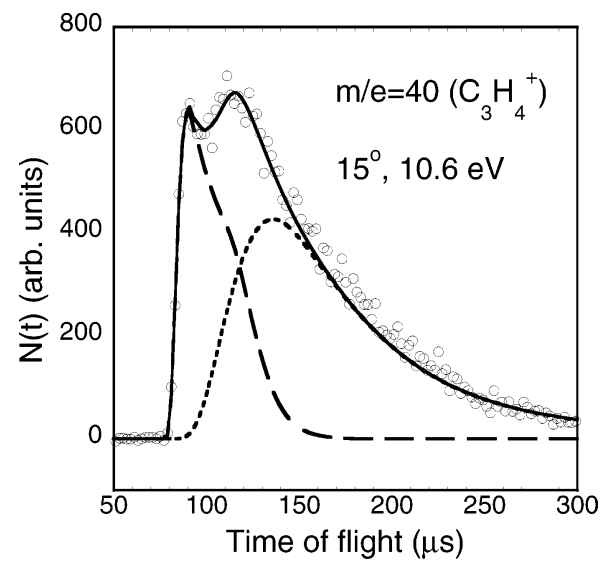

Figure 9. Time-of-flight spectrum of $m / e=40\left(\mathrm{C}_{3} \mathrm{H}_{4}{ }^{+}\right)$, with a source angle of $15^{\circ}$ and a photoionization energy of $10.6 \mathrm{eV}$. The $\mathrm{MgF}_{2}$ window was in place for the collection of this spectrum. The dashedline peak is fit using the dashed line $P\left(\mathrm{E}_{\mathrm{T}}\right)$ in Figure 8 as the primary $P\left(\mathrm{E}_{\mathrm{T}}\right)$ and a secondary $P\left(\mathrm{E}_{\mathrm{T}}\right)$ peaked at $10 \mathrm{kcal} / \mathrm{mol}$ with a FWHM of $2.5 \mathrm{kcal} / \mathrm{mol}$. The dotted-line peak is fit using the thick dotted line $P\left(\mathrm{E}_{\mathrm{T}}\right)$ in Figure 8 as the primary $P\left(\mathrm{E}_{\mathrm{T}}\right)$ and the secondary $P\left(\mathrm{E}_{\mathrm{T}}\right)$ shown in Figure 10. Both peaks result from $\mathrm{C}-\mathrm{C}$ fission of 1-buten-2-yl radicals to produce allene + methyl. Our assignment of this spectrum to allene rather than propyne is confirmed by an additional TOF spectrum of $m / e=40$, with a photoionization energy of $9.8 \mathrm{eV}$, which we have not shown.

The analysis of these spectra is complicated by the fact that both 1-butyne and 1,2-butadiene have nonvertical photoionization onsets, ${ }^{22,23}$ which suggests that their photoionization efficiency may depend somewhat on internal vibrational energy. For this reason, we do not attempt a quantitative measurement of the branching ratio between 1-butyne and 1,2-butadiene; future experiments on isotopically labeled species may prove useful in this regard.

Interestingly, the two fastest peaks are nearly the same size at each ionization energy. This observation is consistent with the possibility that the dominant contribution to each peak is from 1-butyne (from $\mathrm{HBr}$ elimination from 2-bromo-1-butene in the case of the fastest peak, and from $\mathrm{C}-\mathrm{H}$ fission of 1-buten2 -yl radicals in the case of the middle peak), with smaller contributions from 1,2-butadiene (in both peaks) and dissociative ionization of stable 1-buten-2-yl radicals (in the fastest peak), provided that the photoionization efficiency of 1-butyne does not depend too strongly on internal energy. However, in the absence of any information about the onset or efficiency of dissociative ionization of 1-buten-2-yl radicals to form $\mathrm{C}_{4} \mathrm{H}_{6}$, we do not rule out the alternate possibility that the dominant contribution to the fastest peak is instead dissociative ionization of stable 1-buten-2-yl radicals.

3.2.3. C-C Fission to Form Allene + Methyl. Figure 9 shows the TOF spectrum we collected at $m / e=40\left(\mathrm{C}_{3} \mathrm{H}_{4}{ }^{+}\right)$, corresponding to allene products of $\mathrm{C}-\mathrm{C}$ fission of the 1-buten-2-yl radical. We observed the methyl radical partner fragment in this reaction, but because the $m / e=15\left(\mathrm{CH}_{3}{ }^{+}\right)$spectrum contains a contribution from secondary dissociation of $\mathrm{C}_{4} \mathrm{H}_{6}$ products of $\mathrm{HBr}$ elimination, we postpone the presentation of that spectrum until the section on the $\mathrm{C}-\mathrm{C}$ fission of $\mathrm{C}_{4} \mathrm{H}_{6}$. Unlike $\mathrm{C}-\mathrm{H}$ fission, $\mathrm{C}-\mathrm{C}$ fission can impart considerable recoil velocity to both of the nascent fragments, so it is necessary to consider the secondary $P\left(\mathrm{E}_{\mathrm{T}}\right)$ (the distribution of kinetic energies imparted in the $\mathrm{C}-\mathrm{C}$ fission) as well as the primary $P\left(\mathrm{E}_{\mathrm{T}}\right)$ (the distribution of kinetic energies imparted in the $\mathrm{C}-\mathrm{Br}$ fission of the parent 2-bromo-1-butene molecule). Our fit also relies on the assumption that the distribution of secondary recoil velocities

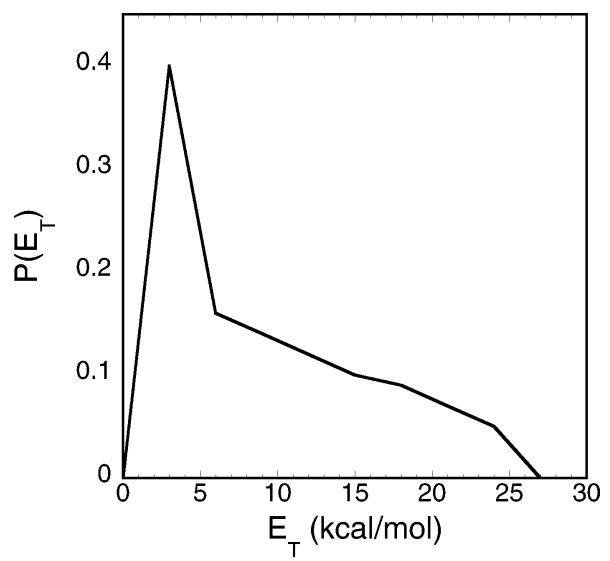

Figure 10. The secondary $P\left(\mathrm{E}_{\mathrm{T}}\right)$ used in the fit of the dotted-line peak in Figure 9.

is isotropic. For these reasons, the uncertainty of our fit to this spectrum is comparatively large.

Because of the bimodality of the $m / e=40$ spectrum, our fit consists of two components. The fast peak, fit by the dashed line in Figure 9, results from the dissociation of $\mathrm{C}_{4} \mathrm{H}_{7}$ radicals whose velocities are given by the $P\left(\mathrm{E}_{\mathrm{T}}\right)$ shown as the dashed line in Figure 8 . This portion of the $m / e=40$ spectrum is best fit by using a $\mathrm{C}-\mathrm{C}$ bond fission $P\left(\mathrm{E}_{\mathrm{T}}\right)$ sharply peaked at $E_{\mathrm{T}}=$ $10 \mathrm{kcal} / \mathrm{mol}$, with a FWHM of $2.5 \mathrm{kcal} / \mathrm{mol}$. A broader distribution of secondary recoil kinetic energies is unable to reproduce the very sharp fast edge of this spectrum. This large amount of kinetic energy imparted to the recoiling fragments is indicative of a large exit barrier (barrier to the reverse reaction), consistent with the computational results shown in Figure 5.

The slow peak, fit by the dotted line in Figure 9, results from the dissociation of $\mathrm{C}_{4} \mathrm{H}_{7}$ radicals whose velocities are given by the $P\left(\mathrm{E}_{\mathrm{T}}\right)$ shown as the bold dotted line in Figure 8. (Note that this same primary $P\left(\mathrm{E}_{\mathrm{T}}\right)$ was used to fit the slow peaks in the $m / e=54$ spectra.) This portion of the $m / e=40$ spectrum is best fit by using the $\mathrm{C}-\mathrm{C}$ bond fission $P\left(\mathrm{E}_{\mathrm{T}}\right)$ shown in Figure 10 . Note that the majority of $\mathrm{C}-\mathrm{C}$ fission events of these slow 1-buten-2-yl radicals impart little recoil kinetic energy to the nascent $m / e=40$ products, but that a minority of $\mathrm{C}-\mathrm{C}$ fissions impart much higher recoil kinetic energy. The small amount of kinetic energy imparted to most of the recoiling fragments in this channel is not consistent with the large exit barrier for $\mathrm{C}-\mathrm{C}$ fission on the ground-state potential energy surface; this suggests that the slow peak may result from $\mathrm{C}-\mathrm{C}$ fission on an excitedstate potential energy surface. We address this point further in the Discussion.

The unexpected consequence of the fit to this spectrum is that the branching fraction to $\mathrm{C}-\mathrm{C}$ fission is not a monotonic function of $E_{\text {int }}$. As $E_{\text {int }}$ increases, branching to $\mathrm{C}-\mathrm{C}$ fission begins to decrease, as expected, when the $\mathrm{C}-\mathrm{H}$ fission channels become energetically accessible, but it reaches a minimum near $E_{\text {int }}=58 \mathrm{kcal} / \mathrm{mol}$, and begins to increase again at higher internal energies. There is a large degree of uncertainty in the fit presented here, but we have been unable to obtain a satisfactory fit to this spectrum that does not have this characteristic, which is further evidence that some of the $\mathrm{C}_{4} \mathrm{H}_{7}$ radicals are dissociating on an excited-state potential energy surface. Our hypothesis that both components of the $m / e=40$ spectrum are due to $\mathrm{C}-\mathrm{C}$ fission of $\mathrm{C}_{4} \mathrm{H}_{7}$ radicals is confirmed by the appearance of momentum-matched $m / e=15$ cofragments; this will be discussed further in the next section.

3.3. Unimolecular Dissociation Channels of the $\mathrm{C}_{4} \mathrm{H}_{6}$ Cofragments of $\mathbf{H B r}$ Elimination. The majority of the $\mathrm{C}_{4} \mathrm{H}_{6}$ 


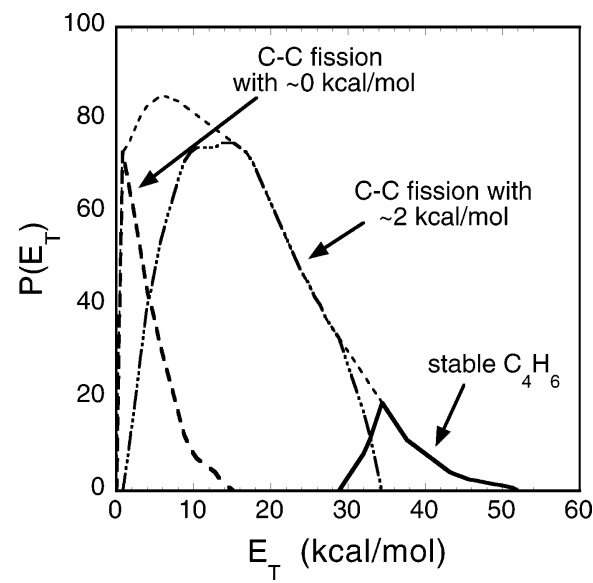

Figure 11. Decomposition of the $\mathrm{HBr}$ elimination $P\left(\mathrm{E}_{\mathrm{T}}\right)$. The solid line represents $\mathrm{C}_{4} \mathrm{H}_{6}$ molecules stable to secondary dissociation, and is used to fit the fastest peak in the $m / e=54$ spectra. We have assumed that almost all of the rest of the $\mathrm{C}_{4} \mathrm{H}_{6}$ cofragments to $\mathrm{HBr}$ elimination undergo $\mathrm{C}-\mathrm{C}$ fission to produce propargyl + methyl. It is not possible to fit the $m / e=39$ spectrum using a single secondary $P\left(\mathrm{E}_{\mathrm{T}}\right)$ for all of the dissociative $\mathrm{C}_{4} \mathrm{H}_{6}$ molecules, so we have divided the remainder of the $\mathrm{HBr}$ elimination $P\left(\mathrm{E}_{\mathrm{T}}\right)$ into two portions and used a different distribution of secondary recoil energy for each of them. This decomposition is arbitrary, and there are many other fits that would prove equally satisfactory.

products of $\mathrm{HBr}$ elimination are unstable to secondary dissociation. A theoretical study by Lee et al. ${ }^{11}$ found that for 1,2-butadiene at an excitation energy of $148 \mathrm{kcal} / \mathrm{mol}, \mathrm{C}_{3} \mathrm{H}_{3}$ (propargyl) $+\mathrm{CH}_{3}$ should be the dominant dissociation channel, with the various available $\mathrm{H}+\mathrm{C}_{4} \mathrm{H}_{5}$ channels constituting a much smaller fraction of the 1,2-butadiene dissociation products. These predictions are consistent with the experimental results of Robinson et al. ${ }^{24}$ on the photodissociation of 1,2-butadiene at $193 \mathrm{~nm}$. At the range of internal energies relevant to our system, we expect that the difference in endothermicities should be of even greater importance in determining product branching than it was at the excitation energy of $148 \mathrm{kcal} / \mathrm{mol}$; since propargyl + methyl is significantly lower in energy than any available set of $\mathrm{H}+\mathrm{C}_{4} \mathrm{H}_{5}$ products, the $\mathrm{C}-\mathrm{C}$ fission should be the dominant channel here as well.

Neither Lee et al. nor Robinson et al. considered 1-butyne in their work. Since 1-butyne can directly dissociate into propargyl + methyl, we expect that $\mathrm{C}-\mathrm{C}$ fission should be the dominant dissociation channel for this isomer also.

3.3.1. Stable $\mathrm{C}_{4} \mathrm{H}_{6}$ Molecules. The portion of the $\mathrm{HBr}$ elimination $P\left(\mathrm{E}_{\mathrm{T}}\right)$ used to fit the fastest peak in the $m / e=54$ spectra (Figure 7) is shown in Figure 11. This $P\left(\mathrm{E}_{\mathrm{T}}\right)$ agrees with the $\mathrm{HBr}$ elimination $P\left(\mathrm{E}_{\mathrm{T}}\right)$ for values of $E_{\mathrm{T}} \geq 34 \mathrm{kcal} /$ mol. This corresponds roughly to internal energies $E_{\text {int }} \leq 71$ $\mathrm{kcal} / \mathrm{mol}$, in satisfactory agreement with the endothermicity of the propargyl + methyl channel, $72 \mathrm{kcal} / \mathrm{mol}$. Due to the possible additional contribution to the fast $m / e=54$ peak from dissociative ionization of stable $\mathrm{C}_{4} \mathrm{H}_{7}$, there is much uncertainty in the stable $\mathrm{C}_{4} \mathrm{H}_{6} \mathrm{P}\left(\mathrm{E}_{\mathrm{T}}\right)$ and in the observed onset of $\mathrm{C}_{4} \mathrm{H}_{6}$ dissociation. However, because the observed onset does agree with the endothermicity of propargyl + methyl, it is indeed possible that the stable $\mathrm{C}_{4} \mathrm{H}_{6} \mathrm{P}\left(\mathrm{E}_{\mathrm{T}}\right)$ resembles the one in Figure 11 , and does contribute to the fastest $m / e=54$ peak in Figure 7.

3.3.2. C-C Fission to Form Propargyl + Methyl. Figure 12 shows the TOF spectrum taken at $m / e=39$, corresponding to propargyl $\left(\mathrm{C}_{3} \mathrm{H}_{3}\right)$ products of $\mathrm{C}-\mathrm{C}$ fission of $\mathrm{C}_{4} \mathrm{H}_{6}$ cofragments of $\mathrm{HBr}$ elimination. To fit this spectrum, we divided the

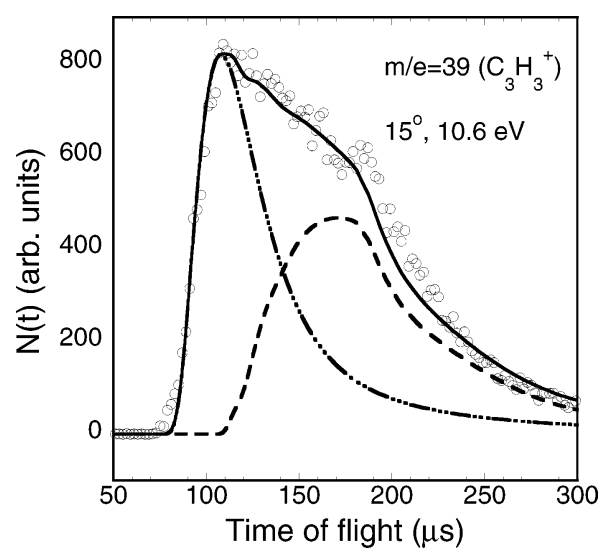

Figure 12. Time-of-flight spectrum of $m / e=39\left(\mathrm{C}_{3} \mathrm{H}_{3}\right)$, with a source angle of $15^{\circ}$ and a photoionization energy of $10.6 \mathrm{eV}$. The $\mathrm{MgF}_{2}$ window was in place for the collection of this spectrum. In fitting this spectrum, we have assumed that all of the $m / e=39$ signal results from $\mathrm{C}-\mathrm{C}$ fission of vibrationally excited $\mathrm{C}_{4} \mathrm{H}_{6}$ cofragments to $\mathrm{HBr}$ elimination. The fit to the fast portion of the spectrum, shown as the dashed-triple-dotted line, is calculated using the dashed-triple-dotted line $P\left(\mathrm{E}_{\mathrm{T}}\right)$ in Figure 11 as the primary $P\left(\mathrm{E}_{\mathrm{T}}\right)$, and the secondary $P\left(\mathrm{E}_{\mathrm{T}}\right)$ shown in Figure 13. The fit to the slow portion of the spectrum, shown as the dashed line, is calculated using the dashed-line $P\left(\mathrm{E}_{\mathrm{T}}\right)$ in Figure 11 as the primary $P\left(\mathrm{E}_{\mathrm{T}}\right)$ and by approximating the secondary recoil energy as $0 \mathrm{kcal} / \mathrm{mol}$. Note that the fit shown here is only one example of many satisfactory fits to this spectrum.

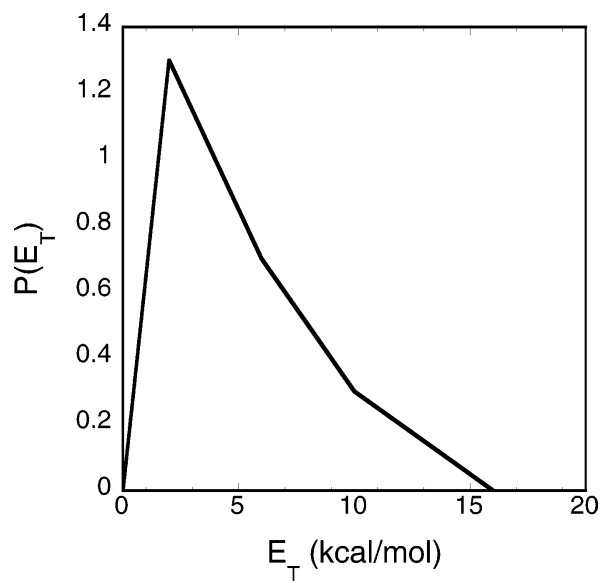

Figure 13. The secondary $P\left(\mathrm{E}_{\mathrm{T}}\right)$ used in the fit of the fast component of the $m / e=39$ spectrum in Figure 12. Note that this $P\left(\mathrm{E}_{\mathrm{T}}\right)$ is dependent upon the decomposition of the primary $\mathrm{HBr}$ elimination $P\left(\mathrm{E}_{\mathrm{T}}\right)$ shown in Figure 11, which produces only one example of many possible fits to the $m / e=39$ data.

remainder of the $\mathrm{HBr}$ elimination $P\left(\mathrm{E}_{\mathrm{T}}\right)$ into two parts and used a different distribution of secondary recoil energies for each of them. For the faster dissociative $\mathrm{C}_{4} \mathrm{H}_{6}$ molecules, shown as the dashed-triple-dotted line in Figure 11, we used the secondary $P\left(\mathrm{E}_{\mathrm{T}}\right)$ shown in Figure 13, in which the secondary recoil energy peaks at $2 \mathrm{kcal} / \mathrm{mol}$. The corresponding contribution to the $m / e$ $=39$ spectrum is shown as the dashed-triple-dotted line in Figure 12. For the slower $\mathrm{C}_{4} \mathrm{H}_{6}$ molecules, shown as the dashed line in Figure 11, we approximate the secondary recoil kinetic energy as $0 \mathrm{kcal} / \mathrm{mol}$, resulting in the dashed-line peak in Figure 12 .

It must be emphasized that the decomposition shown in Figure 11 is entirely arbitrary. It is likely that many other decompositions would result in equally good fits to the $m / e=39$ data. It would therefore be inappropriate to draw any quantitative conclusions from the fit presented here. All that may be inferred with reasonable certainty is that the secondary $P\left(\mathrm{E}_{\mathrm{T}}\right)$ is not constant, but changes in some way with the primary $E_{\mathrm{T}}$. 


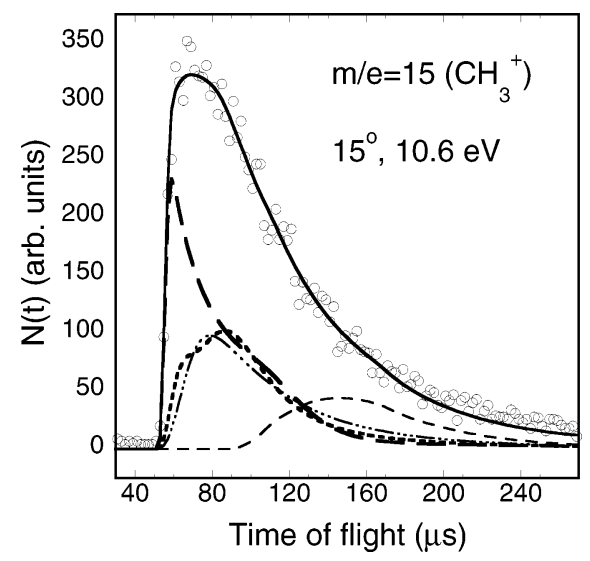

Figure 14. Time-of-flight spectrum of $m / e=15\left(\mathrm{CH}_{3}\right)$, with a source angle of $15^{\circ}$ and a photoionization energy of $10.6 \mathrm{eV}$. The $\mathrm{MgF}_{2}$ window was in place for the collection of this spectrum. Contributing to the signal at this mass are the cofragments to $\mathrm{C}-\mathrm{C}$ fission of 1-buten2-yl radicals and $\mathrm{C}_{4} \mathrm{H}_{6}$ molecules.

It is possible to obtain a satisfactory fit to the $m / e=39$ spectrum if the dashed-triple-dotted $P\left(\mathrm{E}_{\mathrm{T}}\right)$ is modified to include all or part of the stable $\mathrm{C}_{4} \mathrm{H}_{6} P\left(\mathrm{E}_{\mathrm{T}}\right)$. Such a modification does not substantially alter the quality of the fit to the fast edge of the spectrum. The $m / e=39$ spectrum therefore does not allow us to draw any additional conclusions about the nature of the stable $\mathrm{C}_{4} \mathrm{H}_{6} P\left(\mathrm{E}_{\mathrm{T}}\right)$.

The fit shown in Figure 12 is based on the following two assumptions: first, that almost all of the dissociative $\mathrm{C}_{4} \mathrm{H}_{6}$ molecules undergo $\mathrm{C}-\mathrm{C}$ fission to produce propargyl + methyl, so that the entire $\mathrm{HBr}$ elimination $P\left(\mathrm{E}_{\mathrm{T}}\right)$, minus the portion that may result in stable $\mathrm{C}_{4} \mathrm{H}_{6}$ molecules, is a good approximation to the primary $P\left(\mathrm{E}_{\mathrm{T}}\right)$ of $\mathrm{C}_{4} \mathrm{H}_{6}$ molecules undergoing $\mathrm{C}-\mathrm{C}$ fission; and second, that all $m / e=39$ signal is due to photoionization of propargyl radicals, rather than dissociative ionization of $\mathrm{C}_{4} \mathrm{H}_{6}, \mathrm{C}_{3} \mathrm{H}_{4}$, or some other species. The first assumption is based on the RRKM calculations of Lee et al.,"11 discussed above. The second assumption is based on the fact that the momentum-matched partners to both components of the $m / e=39$ spectrum appear in the $m / e=15$ spectrum. The appearance energies of $\mathrm{CH}_{3}$ from $\mathrm{C}_{3} \mathrm{H}_{4}$ and $\mathrm{C}_{4} \mathrm{H}_{6}$ are far too high for these contributions to the $m / e=15$ spectrum to be due to dissociative ionization.

Figure 14 shows the TOF spectrum taken at $m / e=15$. This spectrum contains contributions from methyl radicals resulting from $\mathrm{C}-\mathrm{C}$ fission of $\mathrm{C}_{4} \mathrm{H}_{7}$ radicals and $\mathrm{C}_{4} \mathrm{H}_{6}$ molecules. The peaks shown as the long-dashed and dotted lines are momentummatched to the two peaks of the $m / e=40$ spectrum. The peaks shown as the dashed-triple-dotted and short-dashed lines are momentum-matched to the fast and slow peaks in the $m / e=$ 39 spectrum.

3.3.3. $\mathrm{C}-\mathrm{H}$ Fission to Form $\mathrm{C}_{4} \mathrm{H}_{5}+\mathrm{H}$. Figure 15 shows TOF spectra taken at $m / e=53\left(\mathrm{C}_{4} \mathrm{H}_{5}{ }^{+}\right)$at three different ionization energies. The fastest signal, fit by the solid-line peak, matches well to the stable $\mathrm{C}_{4} \mathrm{H}_{7} P\left(\mathrm{E}_{\mathrm{T}}\right)$, as well as the stable $\mathrm{C}_{4} \mathrm{H}_{6} P\left(\mathrm{E}_{\mathrm{T}}\right)$, and probably contains contributions from dissociative ionization of both. The slowest, dotted-line peak is derived from the same $P\left(\mathrm{E}_{\mathrm{T}}\right)$ as was used to fit the slowest peak in the $m / e=54$ spectra in Figure 7. This peak probably results from dissociative ionization of the slow, vibrationally excited $\mathrm{C}_{4} \mathrm{H}_{6}$ products of $\mathrm{C}-\mathrm{H}$ fission of 1-buten-2-yl radicals. To produce the fits shown in Figure 15, we have assumed that all $\mathrm{C}_{4} \mathrm{H}_{6}$ fragments in this peak are dissociatively ionized with equal efficiency, but this assumption may not be valid at low ionization energies. The relatively slight underfitting of the $9.6 \mathrm{eV}$

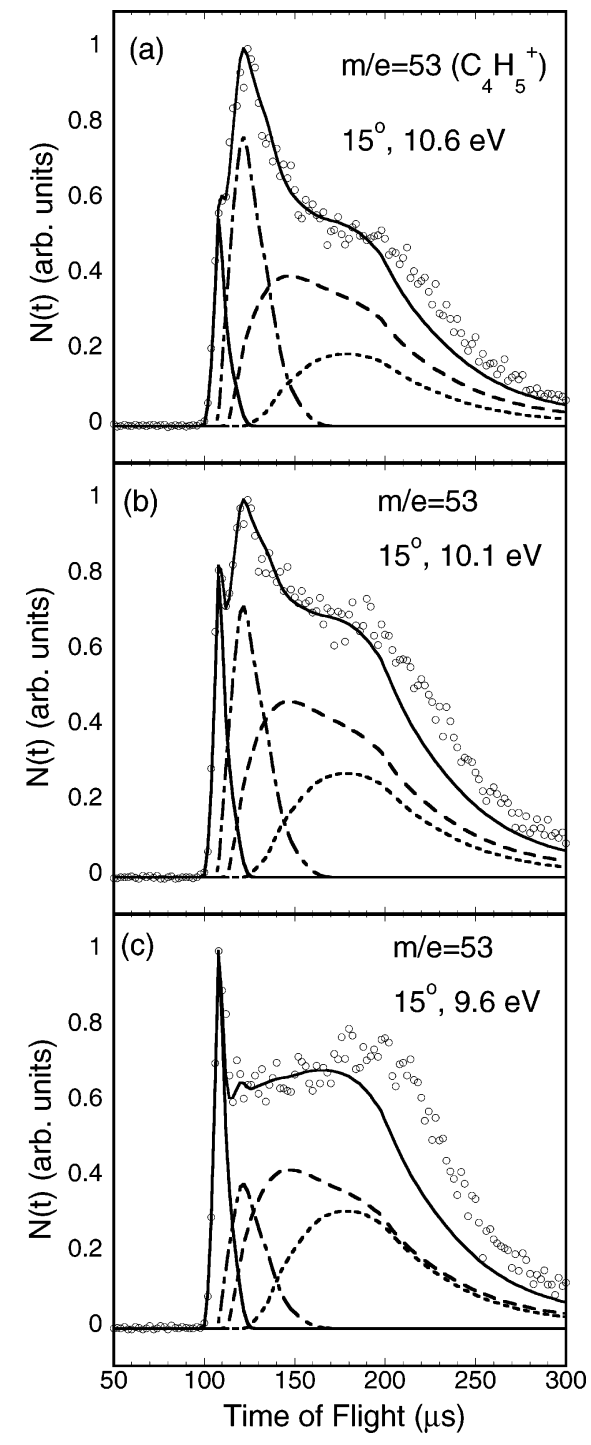

Figure 15. Time-of-flight spectra of $m / e=53\left(\mathrm{C}_{4} \mathrm{H}_{5}\right)$, with a source angle of $15^{\circ}$ and photoionization energies of $10.6 \mathrm{eV}$ (a), $10.1 \mathrm{eV}(\mathrm{b})$, and $9.6 \mathrm{eV}$ (c). The $\mathrm{MgF}_{2}$ window was in place for all three spectra. The solid-line peak probably contains contributions from the dissociative ionization of stable 1-buten-2-yl radicals and stable $\mathrm{C}_{4} \mathrm{H}_{6}$ products of $\mathrm{HBr}$ elimination. The dotted-line peak is fit by the dotted-line $P\left(\mathrm{E}_{\mathrm{T}}\right)$ in Figure 8, corresponding to the dissociative ionization of slow $\mathrm{C}_{4} \mathrm{H}_{6}$ products of $\mathrm{C}-\mathrm{H}$ fission of 1-buten-2-yl radicals. The dashed-line peak is calculated from the $P\left(\mathrm{E}_{\mathrm{T}}\right)$ in Figure 16, and corresponds to $\mathrm{C}-\mathrm{H}$ fission of $\mathrm{C}_{4} \mathrm{H}_{6}$ products of $\mathrm{HBr}$ elimination. The dashed-dotted-line peak is calculated from the dashed-dotted-line $P\left(\mathrm{E}_{\mathrm{T}}\right)$ in Figure 8, but the presence of this peak is surprising (see text). The underfit signal at arrival times greater than $200 \mu \mathrm{s}$ is too slow to be due to photodissociation of 2-bromo-1-butene or of its dimer, and may be the result of beam scatter.

spectrum in the range of 170 to $200 \mu$ s suggests that at this ionization energy the low-kinetic-energy $\mathrm{C}_{4} \mathrm{H}_{6}$ molecules within the dotted-line peak are dissociatively ionized with slightly greater efficiency than the higher-kinetic-energy molecules. (The underfit signal at arrival times greater than $200 \mu$ s is too slow to be due to photodissociation of 2-bromo-1-butene or of its dimer, and may be the result of beam scatter.)

The dashed-dotted-line peak is derived from the same $P\left(\mathrm{E}_{\mathrm{T}}\right)$ as was used to fit the middle peak in the $m / e=54$ spectra. In the $m / e=54$ spectra, this peak resulted from the $\mathrm{C}-\mathrm{H}$ fission of $\mathrm{C}_{4} \mathrm{H}_{7}$ radicals with internal energies just above the threshold to $\mathrm{C}-\mathrm{H}$ fission. Although this $P\left(\mathrm{E}_{\mathrm{T}}\right)$ fits the large peak in the 10.6 and $10.1 \mathrm{eV}$ spectra very well, there is no physical reason 


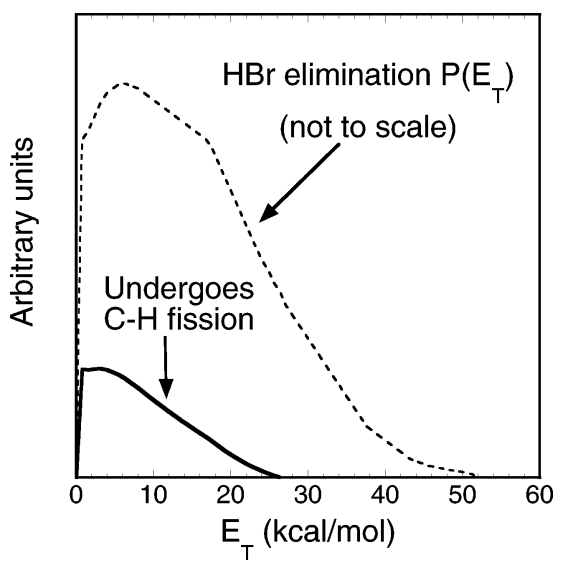

Figure 16. The solid line is the $P\left(\mathrm{E}_{\mathrm{T}}\right)$ used to calculate the dashedline peak of the spectra in Figure 15. This $P\left(\mathrm{E}_{\mathrm{T}}\right)$ was created by assuming that $\mathrm{C}-\mathrm{H}$ fission of $\mathrm{C}_{4} \mathrm{H}_{6}$ products of $\mathrm{HBr}$ elimination begins at an $E_{\mathrm{T}}$ of $26 \mathrm{kcal} / \mathrm{mol}(8 \mathrm{kcal} / \mathrm{mol}$ less than the threshold for $\mathrm{C}-\mathrm{C}$ fission), and that the fraction of $\mathrm{C}_{4} \mathrm{H}_{6}$ molecules undergoing $\mathrm{C}-\mathrm{H}$ fission increases linearly with decreasing $E_{\mathrm{T}}$. The entire $\mathrm{HBr}$ elimination $P\left(\mathrm{E}_{\mathrm{T}}\right)$ is shown for the purpose of comparing the shapes, but not the sizes, of the $P\left(\mathrm{E}_{\mathrm{T}}\right) \mathrm{s}$. We are unable to determine the absolute fraction of the $\mathrm{C}_{4} \mathrm{H}_{6}$ molecules that undergo $\mathrm{C}-\mathrm{H}$ fission, and in our fit of the $m / e=39$ spectrum we have assumed that this fraction is very small.

these $\mathrm{C}_{4} \mathrm{H}_{6}$ products of $\mathrm{C}-\mathrm{H}$ fission should produce signal at $m / e=53$. These molecules do not have enough internal energy to undergo secondary dissociation or dissociative ionization. It is possible that this signal at $m / e=53$ is due to a completely different process, and that the agreement with the near-threshold $\mathrm{C}-\mathrm{H}$ fission peak is fortuitous. For example, in their study of the photodissociation of cis-1-bromopropene, Morton et al. ${ }^{2}$ postulated the existence of an $\mathrm{H}_{2}$ elimination channel from the parent molecule, the products of which would then undergo $\mathrm{C}-\mathrm{Br}$ fission to produce propargyl radicals. It is possible that a similar reaction is occurring here. We have located a transition state for the $\mathrm{H}_{2}$ elimination from 2-bromo-1-butene to produce 2-bromo-1,2-butadiene $+\mathrm{H}_{2}$. We have confirmed the identity of this transition state using an intrinsic reaction coordinate (IRC) calculation and have found its energy at the G2(CC,MP2) level ${ }^{16}$ to lie $85 \mathrm{kcal} / \mathrm{mol}$ above that of 2-bromo-1-butene.

The dashed-line peak is calculated from the $P\left(\mathrm{E}_{\mathrm{T}}\right)$ in Figure 16 , the estimated expected translational energy distribution of the $\mathrm{C}_{4} \mathrm{H}_{6}$ cofragments of $\mathrm{HBr}$ elimination that undergo $\mathrm{C}-\mathrm{H}$ fission to form $\mathrm{C}_{4} \mathrm{H}_{5}$. Since the lowest-energy $\mathrm{C}-\mathrm{H}$ fission channel is $8 \mathrm{kcal} / \mathrm{mol}$ more endothermic than the $\mathrm{C}-\mathrm{C}$ fission channel to produce propargyl + methyl, the threshold $E_{\mathrm{T}}$ at which $\mathrm{C}-\mathrm{H}$ fission first takes place is about $26 \mathrm{kcal} / \mathrm{mol}, 8$ $\mathrm{kcal} / \mathrm{mol}$ less than the threshold for $\mathrm{C}-\mathrm{C}$ fission. We have made the approximation that the relative branching to $\mathrm{C}-\mathrm{H}$ fission increases linearly with decreasing $E_{\mathrm{T}}$. Because the relative photionization cross-sections of the propargyl radical and the various $\mathrm{C}_{4} \mathrm{H}_{5}$ isomers are not known, we are unable to determine the absolute branching to $\mathrm{C}-\mathrm{H}$ fission.

\section{Discussion}

Despite the complexity of the system, we have been able to draw a number of firm conclusions about the dissociation of 2-bromo-1-butene and the 1-buten-2-yl radical, which we recapitulate here.

The barrier to the lowest-energy dissociation channel of the 1-buten-2-yl radical was derived from the TOF spectrum of the stable radicals $(m / e=55)$ and found to be $30.7 \pm 2 \mathrm{kcal} / \mathrm{mol}$. There is a gap between the arrival times of the stable $\mathrm{C}_{4} \mathrm{H}_{7}$ radicals and the arrival times of the highest kinetic-energy $\mathrm{C}-\mathrm{H}$

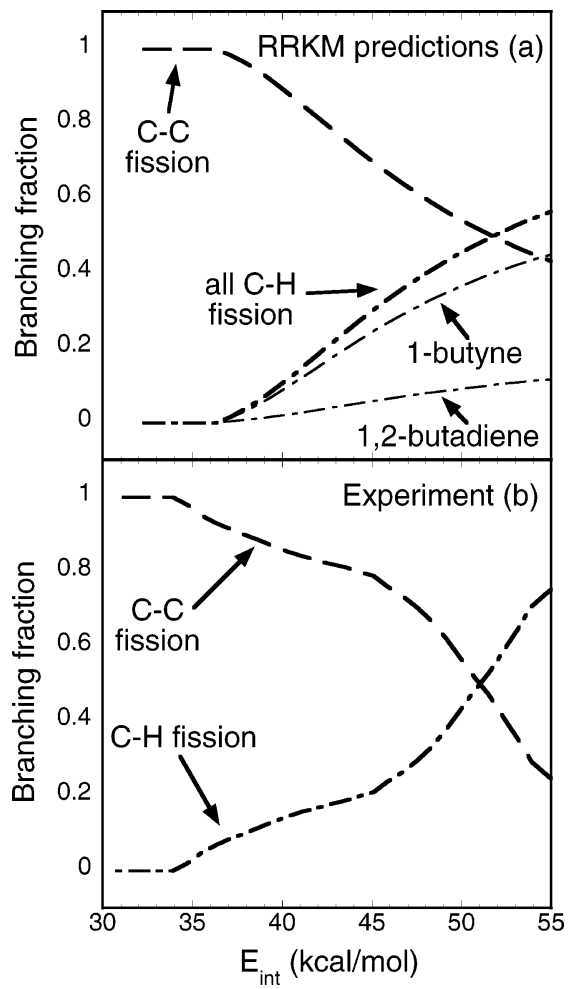

Figure 17. RRKM-predicted (a) and experimentally observed (b) branching between $\mathrm{C}-\mathrm{C}$ fission and $\mathrm{C}-\mathrm{H}$ fission of the 1-buten-2-yl radical, as a function of internal energy.

fission products. This observation is in agreement with Miller's G3//B3LYP calculations, in which $\mathrm{C}-\mathrm{C}$ fission to form allene + methyl was identified as the lowest-energy channel, with a barrier of $31.8 \pm 2 \mathrm{kcal} / \mathrm{mol}^{6}$

Because of the overlap between the peaks of the $m / e=54$ spectra, there is somewhat more uncertainty in our experimental value of the barrier to the lowest-energy $\mathrm{C}-\mathrm{H}$ fission channel. From the range of satisfactory fits we have obtained for these spectra, we find that the barrier to $\mathrm{C}-\mathrm{H}$ fission is $36.7 \pm 4$ $\mathrm{kcal} / \mathrm{mol}$. Again, this value agrees well with Miller's calculations; she found a $36.7 \pm 2 \mathrm{kcal} / \mathrm{mol}$ barrier to form $\mathrm{H}+1,2$ butadiene and a $36.8 \pm 2 \mathrm{kcal} / \mathrm{mol}$ barrier to form $\mathrm{H}+1$-butyne.

In comparison, zero-point-corrected calculations at the B3LYP level of theory with the 6-31G(d) basis set give the following barriers: $30.3 \mathrm{kcal} / \mathrm{mol}$ to allene $+\mathrm{CH}_{3}, 41.3 \mathrm{kcal} / \mathrm{mol}$ to 1-butyne $+\mathrm{H}$, and $36.5 \mathrm{kcal} / \mathrm{mol}$ to 1,2 -butadiene $+\mathrm{H}$. These barriers suggest that at internal energies just above the lowest barrier to $\mathrm{C}-\mathrm{H}$ fission, the $\mathrm{C}_{4} \mathrm{H}_{6}$ products of $\mathrm{C}-\mathrm{H}$ fission would be mostly 1,2-butadiene, but this prediction is not consistent with our observed photoionization efficiency of these $\mathrm{C}_{4} \mathrm{H}_{6}$ products. We conclude therefore that the G3 energy correction to the B3LYP/6-31G(d) calculations, while time-consuming for a system of this size, is necessary for even a qualitatively correct prediction of the dissociation products.

Figure 17 shows the observed branching compared to the RRKM predicted branching. This plot is restricted to those internal energies at which there is no contribution from the lowkinetic-energy $\mathrm{C}-\mathrm{Br}$ bond fission channel (which probably produces $\mathrm{C}_{4} \mathrm{H}_{7}$ radicals in an excited electronic state, for which RRKM predictions based on the ground-state potential energy surface are not valid). The agreement between experiment and the RRKM predictions is satisfactory, but RRKM theory somewhat overestimates the branching to $\mathrm{C}-\mathrm{H}$ fission. This difference may result from a combination of the anharmonicity of the vibrational modes of the transition states, which was not 
taken into account in the RRKM calculations, and our neglect of the nonthermal distribution of rotational energy imparted to the nascent radicals.

We observed behavior of the $\mathrm{C}_{4} \mathrm{H}_{7}$ radicals formed in the low-kinetic-energy $\mathrm{C}-\mathrm{Br}$ fission channel that is markedly different from what is expected of ground-state 1-buten-2-yl radicals and suggests that they are formed in a low-lying excited electronic state. The branching to $\mathrm{C}-\mathrm{C}$ fission is greater than expected of radicals in their ground electronic state. The recoil energy imparted to products of $\mathrm{C}-\mathrm{C}$ fission of low-kineticenergy radicals is much less than that imparted to the products of $\mathrm{C}-\mathrm{C}$ fission of the high-kinetic-energy radicals, and is not consistent with the large calculated exit barrier for the $\mathrm{C}-\mathrm{C}$ fission channel as shown in Figure 5. The $\mathrm{C}_{4} \mathrm{H}_{6}$ products of $\mathrm{C}-\mathrm{H}$ fission of these low-kinetic-energy radicals exhibit much different photoionization efficiency than do the $\mathrm{C}-\mathrm{H}$ fission products of the high-kinetic-energy radicals, which suggests that the branching to 1,2-butadiene (as opposed to 1-butyne) is greater than expected of radicals in their ground electronic state. Calculations by Levchenko and Krylov ${ }^{13}$ indicate a doublet $n$ $\leftarrow \pi$ excited state of the 1-buten-2-yl radical with adiabatic energy $64 \pm 5 \mathrm{kcal} / \mathrm{mol}$ relative to the ground electronic state, uncorrected for zero-point vibrational energy. We conclude that the low-kinetic-energy $\mathrm{C}-\mathrm{Br}$ fission channel probably produces 1-buten-2-yl radicals in the ${ }^{2}(n \leftarrow \pi)$ state. A future theoretical study of the expected dissociation dynamics of excited-state 1-buten-2-yl radicals is necessary to confirm this assignment.

In addition to $\mathrm{C}-\mathrm{Br}$ fission, some of the 2-bromo-1-butene molecules underwent $\mathrm{HBr}$ elimination. Because only those $\mathrm{C}_{4} \mathrm{H}_{6}$ cofragments to $\mathrm{HBr}$ elimination with very high kinetic energies contributed to the $m / e=54$ spectra, we conclude that most of these cofragments are unstable to secondary dissociation. Some, if not all, of the dissociative $\mathrm{C}_{4} \mathrm{H}_{6}$ cofragments to $\mathrm{HBr}$ elimination underwent $\mathrm{C}-\mathrm{C}$ fission to form propargyl + methyl. (It is probable that some of the dissociative $\mathrm{C}_{4} \mathrm{H}_{6}$ molecules underwent $\mathrm{C}-\mathrm{H}$ fission, as indicated by the dashed-line peak in the $m / e=53$ spectra, but enough uncertainties exist in these spectra that we refrain from concluding that we definitely observed this channel.)

The distribution of secondary recoil velocities imparted in $\mathrm{C}-\mathrm{C}$ fission of $\mathrm{C}_{4} \mathrm{H}_{6}$ cofragments to $\mathrm{HBr}$ elimination depends on the primary recoil velocity of the $\mathrm{C}_{4} \mathrm{H}_{6}$ molecules. The $\mathrm{C}_{4} \mathrm{H}_{6}$ molecules with higher kinetic energies impart more recoil velocity to the nascent $\mathrm{C}_{3} \mathrm{H}_{3}$ and $\mathrm{CH}_{3}$ fragments than do the $\mathrm{C}_{4} \mathrm{H}_{6}$ molecules with lower kinetic energies.

The slowest signal in the $m / e=39$ and $m / e=15$ spectra results from $\mathrm{C}-\mathrm{C}$ fission of $\mathrm{C}_{4} \mathrm{H}_{6}$ molecules with low kinetic energy, in which very little recoil (less than $2 \mathrm{kcal} / \mathrm{mol}$ ) is imparted to the nascent propargyl and methyl radical fragments. In contrast, when Robinson et al. ${ }^{24}$ photodissociated 1,2butadiene at $193 \mathrm{~nm}$, they observed a $P\left(\mathrm{E}_{\mathrm{T}}\right)$ for the $\mathrm{C}-\mathrm{C}$ fission channel that peaked at $5 \mathrm{kcal} / \mathrm{mol}$ and extended to $27 \mathrm{kcal} / \mathrm{mol}$, as shown in Figure 5(a) of their work. That our results differ significantly from those of Robinson et al. suggests that in the Robinson et al. experiment, dissociation of 1,2-butadiene may have proceeded on an excited-state potential energy surface.

The 1-buten-2-yl radical acts as an intermediate in such reactions as the methyl-initiated pyrolysis of allene, investigated by Goos et al., ${ }^{8}$ and the oxidation of 1-butyne, studied by Belmekki et al. ${ }^{9}$ The 1-buten-2-yl radical is not explicitly mentioned in the latter study but is the intermediate in reaction 5 of Table III in that work, $1-\mathrm{C}_{4} \mathrm{H}_{6} \rightarrow \mathrm{CH}_{3}+\mathrm{aC}_{3} \mathrm{H}_{4}$. In modeling this reaction, Belmekki et al. used Arrhenius parameters derived for the analogous reaction of propyne, $\mathrm{H}+$ propyne $\rightarrow$ 2-propenyl $\rightarrow \mathrm{H}+$ allene..$^{25}$ Because the barrier to 2-propenyl $\rightarrow \mathrm{H}+$ allene is more than $6 \mathrm{kcal} / \mathrm{mol}$ higher than the barrier to 1-buten-2-yl $\rightarrow \mathrm{CH}_{3}+$ allene, ${ }^{1,6,26}$ the use of parameters specific to the four-carbon system may result in a better model. In their work on the allene + methyl pyrolysis at temperatures of 795 and $945 \mathrm{~K}$ and a pressure of 130 millibar, Goos et al. model the dissociation of the 1-buten-2-yl radical using activation energies that are significantly higher than what we obtained, either in this study or in Miller's computational work. For the $\mathrm{C}-\mathrm{C}$ fission reaction they used an activation energy of $51 \mathrm{kcal} / \mathrm{mol},{ }^{27}$ corresponding to a barrier height of about $49 \mathrm{kcal} / \mathrm{mol}$, compared to our value of $31 \mathrm{kcal} / \mathrm{mol}$. For the $\mathrm{C}-\mathrm{H}$ fission channels, they used an activation energy of $49 \mathrm{kcal} / \mathrm{mol}$, or a barrier height of about $47 \mathrm{kcal} / \mathrm{mol},{ }^{27}$ compared to our $37 \mathrm{kcal} / \mathrm{mol}$. Those authors note that they were able to obtain only qualitative agreement between their model's predictions and their experimental results, but it is unclear to what extent this lack of agreement is related to the parameters used for the reactions involving the 1-buten-2-yl radical. It is possible that collision-induced isomerization to the 1-methylallyl radical resulted in a complex set of elementary steps contributing to their empirical rate parameters.

Several aspects of the dissociation of 2-bromo-1-butene and the 1-buten-2-yl radical remain unexplained by the data we have presented. We were unable to identify conclusively the $\mathrm{C}_{4} \mathrm{H}_{6}$ isomers or mixtures of isomers that were formed via $\mathrm{C}-\mathrm{H}$ fission of the 1-buten-2-yl radical and via $\mathrm{HBr}$ elimination from 2-bromo-1-butene. RRKM calculations suggest that each of these processes should form a mixture of 1-butyne and 1,2butadiene. Although the ionization energy of 1-butyne is 0.9 $\mathrm{eV}$ higher than that of 1,2-butadiene, it is expected that the photoionization efficiency of each of these isomers should depend on internal energy, ${ }^{22,23}$ thus hampering our ability to distinguish between them using tunable VUV photoionization. We suggest that this experiment be repeated using a selectively deuterated precursor as a means of better identifying the $\mathrm{C}_{4} \mathrm{H}_{6}$ isomers being formed.

Lack of knowledge of the internal energy of the nascent $\mathrm{HBr}$ molecules was a hindrance to our understanding of the dissociation of the $\mathrm{C}_{4} \mathrm{H}_{6}$ cofragments to $\mathrm{HBr}$ elimination. If a direct measurement could be made of the rotational and vibrational energy distribution of the $\mathrm{HBr}$ fragments, it would allow for a more exact determination of the relationship between the translational energy and the internal energy of these $\mathrm{C}_{4} \mathrm{H}_{6}$ cofragments. An ion imaging experiment would be ideal for this purpose, because it allows for the resolution of the $\mathrm{HBr}$ internal state distribution as a function of velocity.

The source of the dashed-dotted-line peak in the $m / e=53$ spectra remains unexplained. We have presented the hypothesis that some of the parent 2-bromo-1-butene molecules underwent $\mathrm{H}_{2}$ elimination followed by $\mathrm{C}-\mathrm{Br}$ fission, but none of our other data can provide a confirmation or refutation of this hypothesis. There was too much background noise at $m / e=2$ for a TOF spectrum at this mass-to-charge ratio to be useful. The presence or absence of $\mathrm{H}_{2}$ elimination as a primary dissociation channel remains unresolved.

Plans for future work within our group include studies of the unimolecular dissociation of other straight-chain $\mathrm{C}_{4} \mathrm{H}_{7}$ radical isomers. Data have been collected for the photodissociation of 2-chloro-2-butene and 4-chloro-1-butene, precursors to the 2-buten-2-yl and 3-buten-1-yl radicals. The study of the 3-buten1-yl radical, in particular, is expected to provide an interesting test of our ability to predict the competition between dissociation and isomerization channels of unsaturated hydrocarbon radicals. 
Acknowledgment. This work was supported by the National Science Foundation under grant number CHE-0109588 and renewal grant number CHE 0403471. The Chemical Dynamics Beamline at the ALS is supported by the Director, Office of Science, Office of Basic Energy Sciences, Chemical Sciences Division of the U.S. Department of Energy under contract number DE-AC03-76SF00098. The ALS facility is supported by the Director, Office of Science, Office of Basic Energy Sciences, Materials Sciences Division of the U.S. Department of Energy, under the same contract. J.L.M. acknowledges the support of a DOD Graduate Fellowship, and M.J.K. acknowledges the support of an NSF Graduate Fellowship. We thank Dr. Melita Morton and Dr. Fei Qi for sharing their preliminary data on this system with us. We acknowledge the Burroughs Wellcome Fund Interfaces Cross-Disciplinary Training Program at the University of Chicago for partial support of the computer cluster used for some of the calculations presented here.

\section{References and Notes}

(1) Mueller, J. A.; Parsons, B. F.; Butler, L. J.; Qi, F.; Sorkhabi, O.; Suits, A. G. J. Chem. Phys. 2001, 114, 4505.

(2) Morton, M. L.; Miller, J. L.; Butler, L. J.; Qi, F. J. Phys. Chem. A 2002, 106, 10831

(3) Miller, J. L.; Morton, M. L.; Butler, L. J.; Qi, F.; Krisch, M. J.; Shu, J. J. Phys. Chem. A 2002, 106, 10965.

(4) Morton, M. L.; Butler, L. J.; Stephenson, T. A.; Qi, F. J. Chem. Phys. 2002, 116, 2763

(5) Szpunar, D. E.; Morton, M. L.; Butler, L. J.; Regan, P. M. J. Phys. Chem. B 2002, 106, 8086.

(6) Miller, J. L. J. Phys. Chem. A 2004, 108, 2268.

(7) Matheu, D. A.; Green, W. H.; Grenda, J. M. Int. J. Chem. Kinet. 2003, 35, 95 .

(8) Goos, E.; Hippler, H.; Hoyermann, K.; Jürges, B. Phys. Chem. Chem. Phys. 2002, 4, 2011.

(9) Belmekki, N.; Glaude, P. A.; da Costa, I.; Fournet, R.; BattinLeclerc, F. Int. J. Chem. Kinet. 2002, 34, 172. 7783.

(10) Miller, J. A.; and Klippenstein, S. J. J. Phys. Chem. A 2003, 107

(11) Lee, H.-Y.; Kislov, V. V.; Lin, S.-H.; Mebel, A. M.; Neumark, D. M. Chem. Eur. J. 2003, 9, 726 .

(12) Peterka, D., private communication.

(13) Levchenko, S.; Krylov, A., manuscript in preparation.

(14) Myers, T. L.; Kitchen, D. C.; Hu, B.; Butler, L. J. J. Chem. Phys. 1996, 104, 5446.

(15) Glukhovtsev, M. N.; Pross, A.; McGrath, M. P.; Radom, L. J. Chem. Phys. 1995, 103, 1878.

(16) Mebel, A. M.; Morokuma, K.; Lin, M. C. J. Chem. Phys. 1995 103,7414 .

(17) Frisch, M. J.; Trucks, G. W.; Schlegel, H. B.; Scuseria, G. E.; Robb, M. A.; Cheeseman, J. R.; Zakrzewski, V. G.; Montgomery, J. A., Jr.; Stratmann, R. E.; Burant, J. C.; Dapprich, S.; Millam, J. M.; Daniels, A D.; Kudin, K. N.; Strain, M. C.; Farkas, O.; Tomasi, J.; Barone, V.; Cossi, M.; Cammi, R.; Mennucci, B.; Pomelli, C.; Adamo, C.; Clifford, S.; Ochterski, J.; Petersson, G. A.; Ayala, P. Y.; Cui, Q.; Morokuma, K.; Rega, N.; Salvador, P.; Dannenberg, J. J.; Malick, D. K.; Rabuck, A. D.; Raghavachari, K.; Foresman, J. B.; Cioslowski, J.; Ortiz, J. V.; Baboul, A. G.; Stefanov, B. B.; Liu, G.; Liashenko, A.; Piskorz, P.; Komaromi, I.; Gomperts, R. Martin, R. L.; Fox, D. J.; Keith, T.; Al-Laham, M. A.; Peng,

C. Y.; Nanayakkara, A.; Challacombe, M.; Gill, P. M. W.; Johnson, B.; Chen, W.; Wong, M. W.; Andres, J. L.; Gonzalez, C.; Head-Gordon, M.; Replogle, E. S.; Pople, J. A. Gaussian 98, Revision A.11.3, Gaussian, Inc.: Pittsburgh, PA, 2002.

(18) Parsons, B. F.; Butler, L. J.; Ruscic, B. Mol. Phys. 2002, 100, 865

(19) Hase, W. L.; Bunker, D. L. QCPE 2341974.

(20) Lin, S.-R.; Lin, S.-C.; Lee, Y.-C.; Chou, Y.-C.; Chen, I.-C.; Lee, Y.-P. J. Chem. Phys. 2001, 114, 7396.

(21) Baboul, A. G.; Curtiss, L. A.; Redfern, P. C.; Raghavachari, K. J. Chem. Phys. 1999 110, 7650.

(22) Werner, A. S.; Baer, T. J. Chem. Phys. 1975, 62, 2900

(23) Parr, A. C.; Elder, F. A. J. Chem. Phys. 1968, 49, 2659.

(24) Robinson, J. C.; Sun, W.; Harris, S. A.; Qi, F.; Neumark, D. M.; J. Chem. Phys. 2001, 115, 8359.

(25) Wagner, H. G.; Zellner, R. Ber. Bunsen-Ges. Phys. Chem. 1972, 76,518 .

(26) Davis, S. G.; Law, C. K.; Wang, H. J. Phys. Chem. A 1999, 103,

(27) Hoyermann, K., private communication. 